\title{
Metabolomic, Ionomic and Microbial Characterization of Olive Xylem Sap Reveals Differences According to Plant Age and Genotype
}

\author{
Manuel Anguita-Maeso 1®D, Carmen Haro ${ }^{1}$, Miguel Montes-Borrego ${ }^{1}$, Leonardo De La Fuente ${ }^{2}($, \\ Juan A. Navas-Cortés ${ }^{1, *(D)}$ and Blanca B. Landa ${ }^{1, *(D)}$ \\ 1 Department of Crop Protection, Institute for Sustainable Agriculture, Spanish National Research \\ Council (CSIC), 14004 Córdoba, Spain; manguita@ias.csic.es (M.A.-M.); charo@ias.csic.es (C.H.); \\ mmontesborrego@gmail.com (M.M.-B.) \\ 2 Department of Entomology and Plant Pathology, Auburn University, Auburn, AL 36846, USA; \\ lzd0005@auburn.edu \\ * Correspondence: j.navas@csic.es (J.A.N.-C.); blanca.landa@csic.es (B.B.L.)
}

check for

updates

Citation: Anguita-Maeso, M.; Haro, C.; Montes-Borrego, M.; De La Fuente, L.; Navas-Cortés, J.A.; Landa, B.B. Metabolomic, Ionomic and Microbial Characterization of Olive Xylem Sap Reveals Differences According to Plant Age and Genotype. Agronomy 2021, 11, 1179. https://doi.org/ 10.3390/agronomy11061179

Academic Editor: José

Casanova Gascón

Received: 24 May 2021

Accepted: 8 June 2021

Published: 10 June 2021

Publisher's Note: MDPI stays neutra with regard to jurisdictional claims in published maps and institutional affiliations.

Copyright: (c) 2021 by the authors. Licensee MDPI, Basel, Switzerland. This article is an open access article distributed under the terms and conditions of the Creative Commons Attribution (CC BY) license (https:// creativecommons.org/licenses/by/ $4.0 /)$.

\begin{abstract}
Vascular pathogens are the causal agents of main diseases threatening the health and growth of olive crops worldwide. The use of endophytic microorganisms represents a challenging and promising strategy for management of vascular diseases in olive. Although current research has been focused on analyzing the structure and diversity of the endophytic microbial communities inhabiting the olive xylem, the characterization of this ecological niche has been overlooked and to date remain unexplored, despite that the characterization of the xylem sap composition is essential to unravel the nutritional requirements of xylem-limited microorganisms. In this study, branches from plantlets and adult olive trees of cultivars Picual and Arbequina were selected to characterize the chemical and microbial composition of olive xylem sap extracted using a Scholander pressure chamber. Metabolome and ionome analyses of xylem sap were performed by proton nuclear magnetic resonance (NMR) spectroscopy-based and by inductively coupled plasma with optical emission spectroscopy (ICP-OES), respectively. Olive xylem sap metabolites included a higher relative percentage of sugars $(54.35 \%)$, followed by alcohols $(28.85 \%)$, amino acids $(8.01 \%)$, organic acids $(7.68 \%)$, and osmolytes $(1.12 \%)$. Within each of these groups, the main metabolites in the olive xylem sap were mannitol, ethanol, glutamine, acetic acid, and trigonelline, whereas $\mathrm{K}$ and $\mathrm{Cl}^{-}$were the main element and inorganic anion, respectively. Metabolomic profile varied when comparing olive plant age and genotype. The levels of glucose, fructose, sucrose and mannitol, choline, B and $\mathrm{PO}_{4}{ }^{3-}$ were significantly higher in adult trees than in plantlets for both olive genotypes, whereas $\mathrm{NO}^{3-}$ and $\mathrm{Rb}$ content showed the opposite behavior. On the other hand, levels of aspartic acid, phenylalanine, and Na were significantly higher in 'Picual' than in 'Arbequina', whereas Fe showed the opposite behavior, but only for adult trees. Microbiome composition identified Firmicutes (67\%), Proteobacteria (22\%) and Actinobacteriota (11\%) as the main phyla, while at the genus level Anoxybacillus (52\%), Cutibacterium (7\%), Massilia (6\%), and Pseudomonas (3\%) were the most representative. Both non-supervised hierarchical clustering analysis and supervised PLS-DA analysis differentiated xylem sap chemical and microbial composition first, according to the age of the plant and then by the olive genotype. PLS-DA analysis revealed that B, ethanol, Fe, fructose, glucose, mannitol, sucrose, and Sr, and Anoxybacillus, Cutibacterium, and Bradyrhizobium were the most significant chemical compounds and bacterial genera, respectively, in the discrimination of adult olive trees and plantlets. Knowledge of the chemical composition of xylem sap will lead to a better understanding of the complex nutritional requirements of olive xylem-inhabiting microorganisms, including vascular pathogens and their potential antagonists, and may allow the better design of artificial growing media to improve the culturing of the olive microbiome.
\end{abstract}

Keywords: olive; xylem sap; metabolomics; microbiome; plant age; genotype 


\section{Introduction}

The olive tree (Olea europaea L.) is one of the most important cultivated trees in the Mediterranean Basin due to the numerous beneficial health properties of olive oil which plays a central role in the Mediterranean diet [1]. The wide use of products derived from olive trees, such as table olives and olive oil soaps, cosmetics, etc., is contributing to an increase in the area under olive cultivation and to boosting the economic importance of the olive tree worldwide. The European Union is the main global producer of olive oil with 2.2 Mt, with Spain being the major provider with $1.6 \mathrm{Mt}$ in the 2018/19 season (IOC, www.internationaloliveoil.org; accessed on 20 December 2020).

Olive trees are of great cultural and economic value, but they also exhibit several significant environmental attributes which allow them to survive on poor, shallow and dry soils. These attributes include an extensive root system that promotes drought resistance as well as high adaptability to unfavorable environments, including mountain slopes and hillsides, where olive roots serve to limit soil erosion and increase nutrient retention [2,3]. In addition, olive crops have been identified as important habitats for rich ground flora and fauna where pollinators play an essential role in the maintenance of ecosystem diversity [4] These reasons highlight the importance of olive crop as an economic, environmental, and cultural symbol across the Mediterranean region and reinforce the need of its maintenance and preservation for future generations. However, its viability and survival as a main crop is seriously threatened by vascular plant pathogens such as the soil-borne fungus Verticillium dahliae and the bacterium Xylella fastidiosa. Both pathogens colonize the vascular bundles of the xylem obstructing the sap flow, leading to wilting of plant tissue, and ultimately may also cause the death of the tree, resulting in heavy environmental and economic losses in areas where those pathogens are endemic or have emerged as new outbreaks [5,6].

Xylem vessels play a decisive role for plant growth maintenance providing a main route and a very refined plumbing system for the circulation of micro and macronutrients derived from xylem sap. Indeed, xylem transport of solutes is essential for long and short distance redistribution of nutrients within the host plant which is driven by hydrostatic pressure and water potential [7]. This nutrient flow in the xylem from roots to shoots ensure controlled loading or unloading of ions and metabolites in the xylem and their effective translocation to the required and localized area [8]. Consequently, the characterization of xylem sap composition is essential to obtain information for understanding nutrient fluxes and dynamics which are crucial for maintenance of plant responses and microbial interactions within the xylem that might result in host plant defense reactions against vascular wilt pathogens [9].

Xylem sap contains a wide range of compounds beyond water and minerals. In fact, several studies have revealed that these compounds include amino acids [10,11], organic acids $[12,13]$ and vitamins [14,15]. Nevertheless, xylem sap composition does not remain constant in the host plant, and it can be influenced by diverse factors such as soil water content [16,17], method of xylem sap collection [18], type of organs selected [19], presence of rootstocks and interstocks [20], and incidence of microbial interactions including infection by plant pathogens [21,22], among others. Additionally, the age of the host plant and seasonal changes are factors affecting xylem sap composition [23-25]. Several studies have characterized the xylem sap composition of woody plant species, e.g., [22,26-29]. However, to our knowledge, only one study has characterized the xylem sap composition of olive trees [30], despite it being one of the most remarkable tree crops in the Mediterranean Basin.

Xylem vessels are considered ideal niches for microbial endophytes by providing an effective internal pathway for dispersion throughout the plant and a continuous source of nutrients [31]. However, despite significant progress in research on plant microbiota over the past years, only few publications have revealed the nature and role of the xylem microbiome, and its relationship to plant health and crop productivity [32-38]. Therefore, a thorough knowledge of the microbial communities residing within the xylem vessels of olive trees and their metabolic requirements for growth may be crucial for understanding 
their potential influence on the healthy growth of olive as well as on the resistance shown by specific olive genotypes against vascular plant pathogens $[39,40]$. According to our knowledge, there are no scientific studies addressing the combined study of the chemical and microbial composition of the xylem sap of perennial plant species.

In this work, we have characterized, for the first time, the xylem sap chemical composition together with the xylem residing microbiota of the two olive genotypes most widely cultivated in Spain, and we provide new knowledge on the changes in their metabolomic, ionomic, and microbiome profile according to the plant age and the olive genotype. The characterization of xylem sap composition from olive trees will help to improve our understanding of the nutritional requirements for growth of xylem-inhabiting microorganisms (including those nonculturable yet) that may lead to design suitable culture media, as a first step, to isolate or favor the growth of potential endophytic microorganisms that can be exploited as biological control agents against main vascular pathogens in olive trees.

\section{Materials and Methods}

\subsection{Olive Plant Material and Sampling}

Olive plants from cultivars 'Picual' and 'Arbequina' of different age were used in the study. These olive genotypes are within the most widely cultivated in Spain [41]. Olive adult trees (10-years-old) are grown at an experimental field (sandy loam soil, $\mathrm{pH}$ 8.5, $1.4 \%$ organic matter) located at the Alameda del Obispo Research Station near Córdoba (Southern Spain) $\left(37.5^{\circ} \mathrm{N}, 4.8^{\circ} \mathrm{W}\right.$, altitude $\left.110 \mathrm{~m}\right)$ belonging to the Institute for Sustainable Agriculture from the Spanish National Research Council. The trees are managed according to normal olive cropping practices.

Plantlets (1-year-old) obtained following a standard semi-woody stacking procedure at a commercial olive nursery (Plantas Continental S.A, Córdoba, Spain) were grown in $500 \mathrm{~mL}$ pots containing a perlite:coconut fiber:peat (1.5:5:3.5) mixture amended with $1 \%$ of slow-release fertilizer (Osmocote ${ }^{\circledR}$ Exact standard 15-9-12+2MgO; ICL Specialty Fertilizers, Waardenburg, The Netherlands). Plantlets were grown for 3 months in a growth chamber adjusted to $22 \pm 2{ }^{\circ} \mathrm{C}, 60-80 \%$ relative humidity, and a 14-h photoperiod of fluorescent light of $360 \mu \mathrm{mol} \mathrm{m}{ }^{-2} \mathrm{~s}^{-1}$, were watered as needed, and fertilized every two weeks with $100 \mathrm{~mL}$ Hoagland's nutrient solution.

For xylem sap extraction, four terminal 35-cm-long branches (one per tree) from adult trees and the entire canopy of four plantlets from each olive genotype were selected to characterize the chemical composition of olive xylem sap. All pruned branches were placed in sterile plastic bags, sprayed with distilled water, and kept in a cold room at $4{ }^{\circ} \mathrm{C}$ to avoid desiccation until sample processing within the same day.

\subsection{Xylem Sap Extraction}

Xylem sap was extracted as described previously in Anguita-Maeso et al. [32]. Briefly, a Scholander pressure chamber was used to perform xylem sap extraction from xylem vessels with an external port allowing branches inclusion up to $60 \mathrm{~cm}$ long. After inserting the branch in the super chamber, $2 \mathrm{~cm}$ of the main stem was debarked and disinfested with a sterile paper moistened in ethanol to avoid microbial contamination of the xylem sap from bark and phloem. Ethanol was left to evaporate before sap extraction. The pressure was increased gradually until xylem sap drops were observed, but to a maximum of 25 bars of pressure to avoid external contamination derived from cell rupture.

Xylem sap was collected in a $15 \mathrm{~mL}$ sterile Falcon tube placed on ice. An average of $10 \mathrm{~mL}$ of xylem sap was collected from adult olive trees, while an average of $5 \mathrm{~mL}$ was extracted from olive plantlets. Samples were immediately filtered through a $0.22-\mu \mathrm{m}$ pore MF-Millipore $^{\mathrm{TM}}$ filter (Merck Millipore, Madrid, Spain), and the filtered sap and filters were stored independently at $-80^{\circ} \mathrm{C}$ until analysis. One aliquot of the sample was used to determine the absence of cytosolic contamination by using the malate dehydrogenase assay kit (Sigma) [27] before chemical composition analysis. Two aliquots of $1 \mathrm{~mL}$ each were sent on ice to the Metabolomics and Ionomic Services at the Center for Edaphology and 
Applied Biology of Segura, CSIC, Spain for conducting metabolome and ionome analysis, respectively.

\subsection{Metabolomic and Ionomic Analysis}

Metabolome analysis of xylem sap was performed by proton nuclear magnetic resonance (NMR) spectroscopy as described in [22]. Briefly, frozen xylem olive sap samples were thawed on ice and $18 \%$ (vol/vol) of $\mathrm{D}_{2} \mathrm{O}$ (nmr deutero, Germany), containing $0.1 \%$ 3-(trimethylsilyl) propionic acid-d4 sodium salt (TMSP-d4; Sigma Aldrich) was added as chemical shift reference to a final volume of $220 \mu \mathrm{L}$. The NMR spectra were acquired at $298 \mathrm{~K}$ on a Bruker AVIII HD 500 NMR (Bruker Biospin, Germany) spectrometer (500.13 MHz for $1 \mathrm{H})$ equipped with a $5 \mathrm{~mm}$ CPP BBO cryogenic probe. $1 \mathrm{H}$ spectra were referenced to TMSP signal $(\delta=0.00 \mathrm{ppm})$. Standard one-dimensional spectra were acquired at $298 \mathrm{~K}$ using the "noesypr1d" pulse sequence with water presaturation during relaxation delay and mixing time. Acquired spectra consisted of 128 scans, with 65,000 complex data points and a spectral width of $7211.539 \mathrm{~Hz}$, were processed using Topspin (v3.2; Bruker BioSpin Corp.) and imported to the Chenomx NMR suite (v8.1; Chenomx Inc., Edmonton, AB, Canada) for the targeted identification and quantification of metabolites present in xylem sap.

Ionome analysis was performed by inductively coupled plasma with optical emission spectroscopy (ICP-OES) as described in de la Rosa et al. [42] using an Thermo iCAP 7000 Series Duo instrument (Thermo Scientific, Leicestershire, UK). Briefly, after performing the instrument sensitivity and obtain the calibration curve, the following ICP-OES parameters were used: nebulizer flow, $0.50 \mathrm{~L} \mathrm{~min}^{-1}$; radio frequency power, 1250; sample introduction, $1.50 \mathrm{~mL} \mathrm{~min}{ }^{-1}$; flush time, $15 \mathrm{~s}$; delay time, $20 \mathrm{~s}$; read time, $10 \mathrm{~s}$; wash time, $60 \mathrm{~s}$; no internal standards were used and each sample was read in triplicate. On the other hand, xylem sap anion concentration was determined by ion chromatography (Metrohm AG, Herisau, Switzerland) on a Metrosep A Supp 4 analytical column $(4 \times 125 \mathrm{~mm} 1.8 \mathrm{~mm}$ $\mathrm{Na}_{2} \mathrm{CO}_{3} / 1.7 \mathrm{~mm} \mathrm{NaHCO}$ eluent) as described by Akhtar et al. [43].

\subsection{Microbiome Analysis}

DNA for microbiome analysis was extracted using the DNeasy PowerSoil Kit (QIAGEN). Filters containing the filtered microbiome were placed into PowerBead tubes (Dneasy PowerSoil Kit, QIAGEN, Düsseldorf, Germany) containing $0.5 \mathrm{~mL}$ of Dneasy PowerSoil Kit buffer and $60 \mu \mathrm{l}$ of Kit Solution C1. Cells were homogenized $7 \mathrm{~min}$ at 50 pulses $\cdot \mathrm{s}^{-1}$ with the Tissuelyser LT (QIAGEN) and incubated $1 \mathrm{~h}$ at $60^{\circ} \mathrm{C}$ to increase cell lysis. Then, samples were processed following the DNeasy PowerSoil Kit manufacturer's instructions.

Primers 799F (5'-AACMGGATTAGATACCCKG-3') and 1115R (5'-AGGGTTGCGCTC GTTG-3') targeting the V5-V6 of the 16S rRNA were used for metabarcoding analysis as described before [32]. PCR amplicons were cleaned up before adaptor addition using the Ampure XP magnetic bead system (Beckmann-Coulter, MA, USA). Then, dual barcode indices and sequencing adaptors were attached to each amplicon using the Illumina Nextera XT Index kit (Illumina, Inc., San Diego, CA, USA) following manufacturer's protocol. Purified amplicons were quantified using the Quant-iT ${ }^{\mathrm{TM}}$ PicoGreen ${ }^{\mathrm{TM}}$ dsDNA Assay Kit (Thermo Fisher Scientific, Leicestershire, UK) and equimolecular amounts from each individual sample in $10 \mathrm{mM}$ of Tris were combined. The pooled library was purified with two rounds of Ampure XP cleanup step and sequenced by the Genomics Unit at 'Fundación Parque Científico de Madrid' (Madrid, Spain) using the Illumina MiSeq platform (Nano-V2; PE 2x 250 bp). The ZymoBIOMICS microbial standard (Zymo Research Corp., Irvine, CA, USA) and water (no template DNA) were used as internal positive and negative controls, respectively, for library construction and sequencing. Raw sequence data have been deposited in the Sequence Read Archive (SRA) database at the NCBI under BioProject accession number PRJNA732195. 


\subsection{Statistical and Bioinformatics Analyses}

The effects of the olive genotype and plant age on the chemical composition of xylem sap were determined by analysis of variance (ANOVA) using the lineal models function in rstats package in $R$ [44]. The experimental design consisted of a two-way factorial design with plant age and olive genotype as factors. When the interaction plant age $\mathrm{x}$ olive genotype was significant $(p<0.05)$ single degree of freedom contrasts were performed to disentangle the differences among treatment combinations. Data of metabolites and ions were unified to $\mu \mathrm{M}$ units prior to logarithm transformation to fulfill ANOVA assumption of normality and homogeneity of variance that was previously tested by Shapiro-wilks and Levene's tests using the rtatix and car packages in R, respectively [44,45]. An initial, non-supervised multivariate hierarchical clustering analysis, using Pearson's correlation to measure distance, and an average Ward clustering algorithm of all metabolites measured was performed. Then, a supervised principal least square-discriminant analysis (PLSDA) [46] was used to reduce the number of variables (metabolites) and select the most predictive or discriminative to differentiate the xylem sap composition according to the olive plant age, and then within each plant age according to the olive genotype. Both, hierarchical clustering and PLS-DA analyses were performed using MetaboAnalyst 4.0 (http:/ /www.metaboanalyst.ca; accessed on 2 May 2021 [47]). Data were auto-scaled (mean-centered and divided by the standard deviation of each variable) before analysis.

For microbiome analysis, quality control and adapter trimming of demultiplexed raw fastq 16S rRNA sequences obtained from MiSeq output was performed with FastQC and TrimGalore tools. No truncation and trimming lenght was needed to reach the Phred quality $(Q>30)$ score visualized in MultiQC tool. Quality reads were then analyzed using DADA2 method for the identification of the ASVs (amplicon sequence variants) present in the samples [48] with default parameters and were taxonomically classified using Silva SSU v.138 database. Singletons were discarded for taxonomy assignation and statistical analysis. Differences in bacterial communities were calculated using alphadiversity indexes (Richness and Shannon) at ASV level. The non-parametric Scheirer-RayHare test $(p<0.05)$ was used to assess the effects of the plant age and plant genotype, and their interaction in alpha diversity indexes, using the package rcompanion [49] in R. Beta diversity was analyzed using principal coordinate analysis (PCoA) of weighted UniFrac distance matrix to evaluate similarities among the bacterial communities according to age and genotype. Additionally, the adonis function within the vegan package in $\mathrm{R}$ (999 permutations) was performed to test the effects $(p<0.05)$ of the plant age, genotype, and their interaction. Alpha and beta diversity were conducted rarefying all samples to the minimum number of reads found. Hierarchical clustering analysis and PLS-DA were performed as described above for metabolomic and ionomic data using normalized data on ASV abundance. Finally, a NMDS (non-metric multidimensional scaling) analysis was performed using MetaMDS function within the vegan package in $\mathrm{R}$ based on the BrayCurtis distance measure obtained for the ASV level data. Vectors of significant chemical compounds were fitted onto the NMDS ordination plot using the envfit function of the vegan package and 999 permutations.

\section{Results}

\subsection{Metabolite and Ion Profiles in Olive Xylem Sap}

A total of 30 metabolites were identified in olive xylem sap using NMR, including five organic acids (acetic, formic, fumaric, maleic, and succinic acids), 15 amino acids (alanine, arginine, asparagine, aspartic acid, GABA, glutamic acid, glutamine, isoleucine, leucine, methionine, phenylalanine, proline, threonine, tyrosine, valine), five sugars (glucose, fructose, sucrose, mannitol and myo-inositol), two alcohols (ethanol and methanol), and three other molecules (choline, sarcosine and trigonelline) (Table 1). The vast majority of organic acids, sugars and osmolytes were detected in all samples while amino acids displayed more variability among samples. Thus, the amino acids arginine, asparagine, GABA, methionine and proline were detected in less than half of the samples. In addition, 
the amino acids arginine, asparagine, aspartic acid, and phenylalanine were detected in a higher number of samples of 'Picual' as compared to 'Arbequina', whereas a higher detection of GABA and choline was found in adult trees as compared to plantlets (Table 1).

On the other hand, ICP-OES allowed the detection of 18 elements and five inorganic anions (Table 2). All inorganic anions were detected in all samples studied, while more variable was the detection of other elements, such as Fe and Mn which displayed a higher frequency of detection in adult trees than in plantlets (Table 2).

In general, olive xylem sap metabolites included a higher relative percentage of sugars $(54.35 \%)$, followed by alcohols $(28.85 \%)$, amino acids $(8.01 \%)$, organic acids $(7.68 \%)$, and osmolytes (1.12\%) (Figure 1A). Among the five organic acids detected acetic and formic acids exhibited the highest proportion with $70.72 \%$ and $10.80 \%$ of the total, respectively. Similarly, the amino acids glutamine and glutamic acid were the most abundant in xylem sap, comprising more than $65 \%$ of total amino acids (52.59\% and $14.72 \%$, respectively). Furthermore, mannitol $(51.72 \%)$ and glucose $(20.98 \%)$ showed the greatest levels within all sugar compounds. On the other hand, the alcohol detected at higher proportion was ethanol $(66.03 \%)$, whereas the prevalent osmolyte was trigonelline (55.72\%) (Figure 1B). Ionome analysis revealed that $\mathrm{K}(51.40 \%)$ and $\mathrm{Na}(14.79 \%)$ were the most abundant mineral macroelements, followed by S, Ca, and P $(10.87 \%, 10.39 \%$ and $6.87 \%$, respectively). On the other hand, $\mathrm{Cl}^{-}(40.02 \%)$ and $\mathrm{SO}_{4}{ }^{2-}(26.33 \%)$ were positioned as the prevalent anions found in olive xylem sap (Figure 1C). Other microelements detected included B, Cu, Zn, and $\mathrm{Mn}$ with abundances ranging from $0.68 \%$ to $0.02 \%$, whereas $\mathrm{Ni}, \mathrm{Fe}$, and $\mathrm{Rb}$ were detected at $<0.01 \%$ of the total mineral elements. 


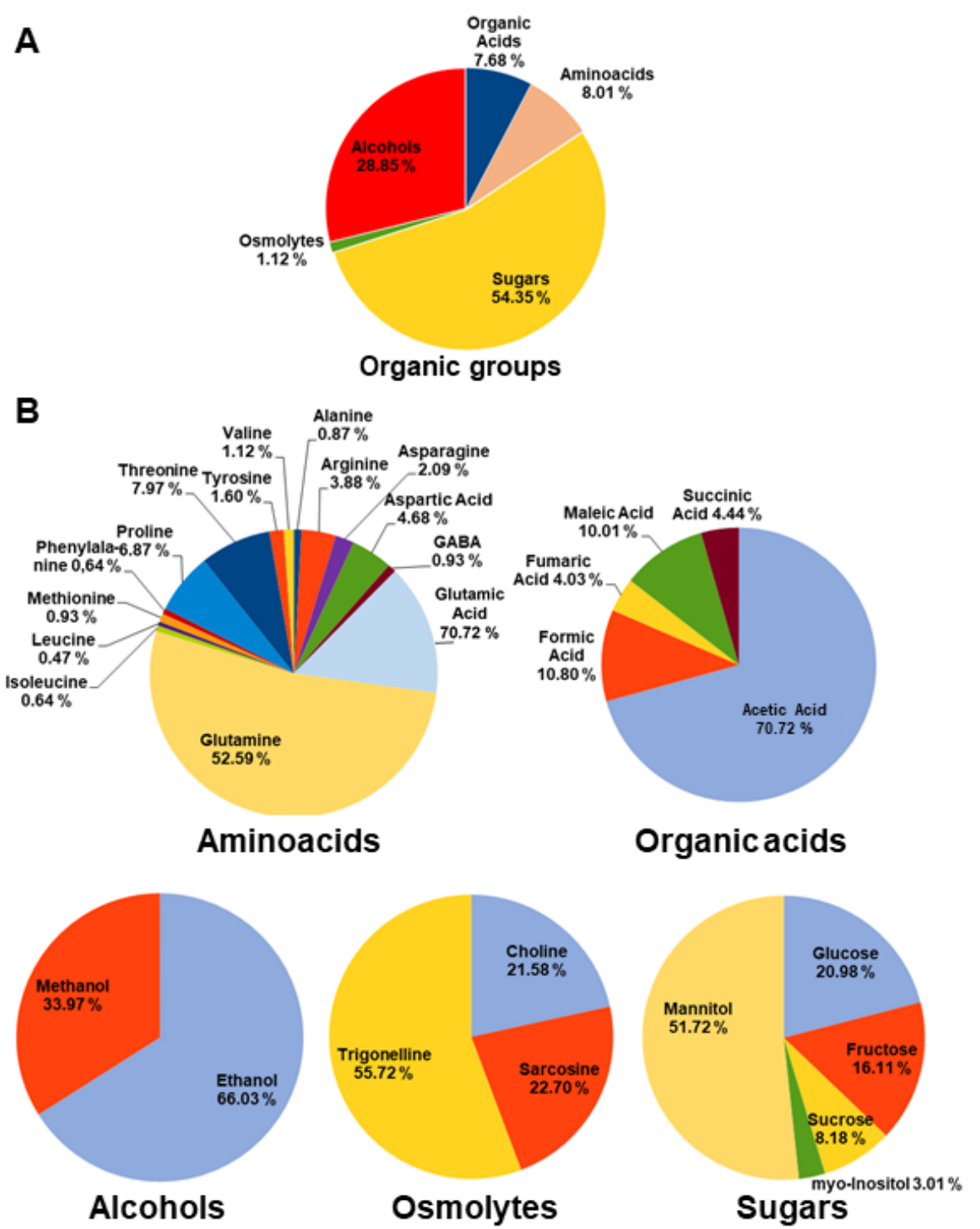

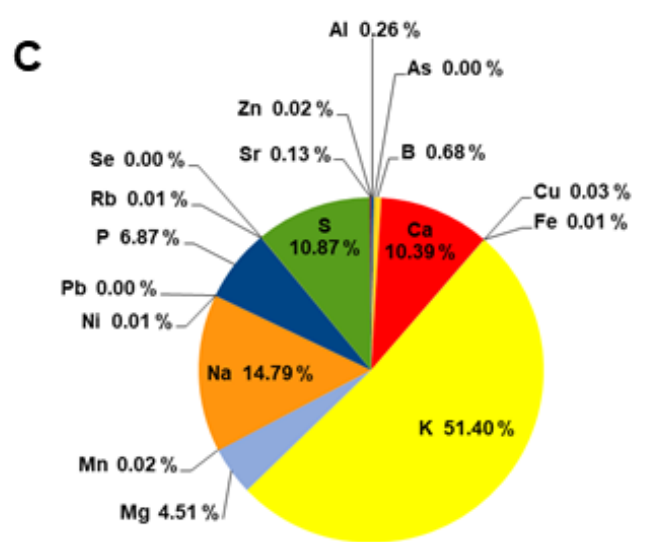

Elements

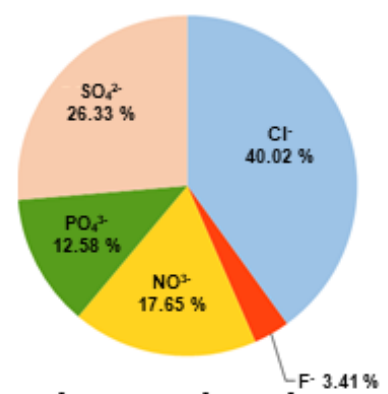

Inorganic anions

Figure 1. Percentage composition of the different organic groups (A), amino acids, organic acids, alcohols, sugars, osmolytes (B) mineral elements and inorganic ions (C) detected in all olive xylem sap samples analyzed in the study. 


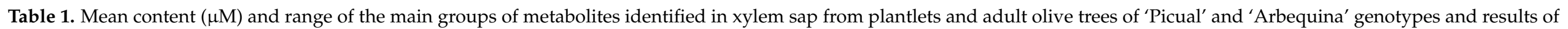

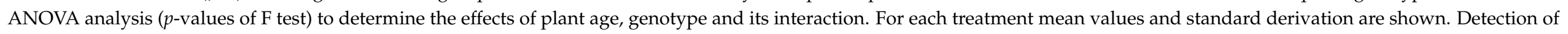
each compound in the total samples tested is displayed in parentheses.

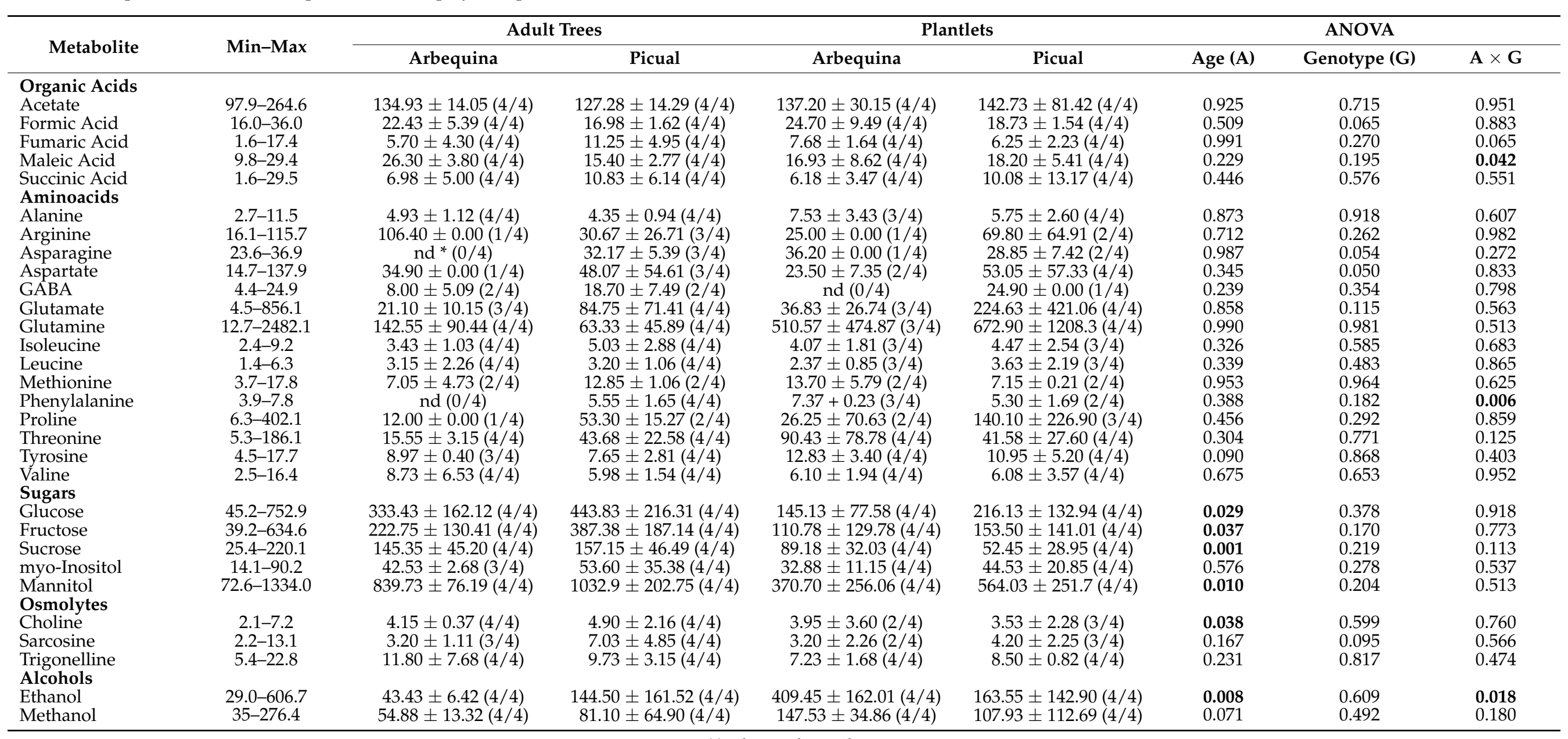




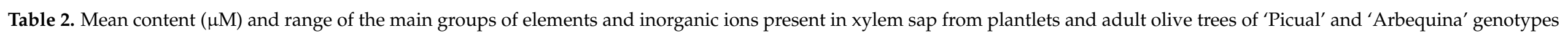

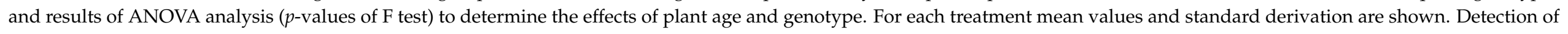
each compound in the total samples tested is displayed in parentheses.

\begin{tabular}{|c|c|c|c|c|c|c|c|c|}
\hline \multirow{2}{*}{ Compound } & \multirow{2}{*}{ Min-Max } & \multicolumn{2}{|c|}{ Adult Trees } & \multicolumn{2}{|c|}{ Plantlets } & \multicolumn{3}{|c|}{ ANOVA } \\
\hline & & Arbequina & Picual & Arbequina & Picual & Age (A) & Genotype (G) & $A \times G$ \\
\hline \multicolumn{9}{|l|}{ Element } \\
\hline $\mathrm{Al}$ & $5.4-41.4$ & $9.63 \pm 5.94(2 / 4)$ & $33.22 \pm 11.61(2 / 4)$ & $13.05 \pm 3.82(2 / 4)$ & $12.38 \pm 8.77(3 / 4)$ & 0.825 & 0.517 & 0.968 \\
\hline As & $0.1-0.5$ & $0.21 \pm 0.08(2 / 4)$ & nd $(0 / 4)$ & $0.41 \pm 0.00(1 / 4)$ & $0.05 \pm 0.00(1 / 4)$ & 0.373 & 0.538 & 0.536 \\
\hline B & $1.4-67.9$ & $49.41 \pm 15.68(4 / 4)$ & $28.19 \pm 10.03(4 / 4)$ & $12.78 \pm 7.37(4 / 4)$ & $10.32 \pm 7.78(3 / 4)$ & 0.002 & 0.089 & 0.630 \\
\hline $\mathrm{Ca}$ & $104.0-1208.0$ & $465.31 \pm 42.70(4 / 4)$ & $372.00 \pm 55.43(4 / 4)$ & $222.61 \pm 216.07(4 / 4)$ & $452.08 \pm 517.03(4 / 4)$ & 0.086 & 0.694 & 0.306 \\
\hline $\mathrm{Cu}$ & $0.3-1.6$ & $1.20 \pm 0.35(4 / 4)$ & $0.91 \pm 0.09(4 / 4)$ & $1.26 \pm 0.63(3 / 4)$ & $0.70 \pm 0.28(4 / 4)$ & 0.195 & 0.544 & 0.807 \\
\hline $\mathrm{Fe}$ & $0.3-1.2$ & $1.03 \pm 0.21(4 / 4)$ & $0.37 \pm 0.02(3 / 4)$ & $0.47 \pm 0.00(1 / 4)$ & $0.58 \pm 0.00(1 / 4)$ & 0.007 & 0.022 & 0.044 \\
\hline K & $1246.6-3571.2$ & $1743.8 \pm 160.4(4 / 4)$ & $1808.8 \pm 320.31(4 / 4)$ & $1556.3 \pm 277.21(4 / 4)$ & $2371.4 \pm 1056.8(4 / 4)$ & 0.765 & 0.177 & 0.244 \\
\hline $\mathrm{Mg}$ & $50.4-879.4$ & $90.00 \pm 9.33(4 / 4)$ & $92.84 \pm 16.94(4 / 4)$ & $156.56 \pm 173.11(4 / 4)$ & $316.95 \pm 388.10(4 / 4)$ & 0.347 & 0.570 & 0.607 \\
\hline $\mathrm{Mn}$ & $0.4-4.3$ & $0.89 \pm 0.05(4 / 4)$ & $0.46 \pm 0.12(4 / 4)$ & $1.53 \pm 0.00(1 / 4)$ & $4.33 \pm 0.00(1 / 4)$ & 0.435 & 0.991 & 0.175 \\
\hline $\mathrm{Na}$ & $156.5-1281.1$ & $410.28 \pm 43.45(4 / 4)$ & $709.86 \pm 22.76(4 / 4)$ & $365.80 \pm 178.67(4 / 4)$ & $666.55 \pm 433.10(4 / 4)$ & 0.332 & 0.024 & 0.997 \\
\hline $\mathrm{Ni}$ & $0.2-0.7$ & $\mathrm{nd} *(0 / 4)$ & $0.33 \pm 0.00(1 / 4)$ & $0.32 \pm 0.00(1 / 4)$ & $0.50 \pm 0.40(2 / 4)$ & 0.538 & 0.504 & 0.991 \\
\hline $\mathrm{P}$ & $34.7-556.0$ & $360.25 \pm 162.99(4 / 4)$ & $198.94 \pm 25.91(4 / 4)$ & $204.80 \pm 155.74(4 / 4)$ & $235.52 \pm 66.57(4 / 4)$ & 0.652 & 0.805 & 0.153 \\
\hline $\mathrm{Pb}$ & $0.07-0.1$ & $0.07 \pm 0.00(1 / 4)$ & nd $(0 / 4)$ & nd $(0 / 4)$ & $0.10 \pm 0.00(1 / 4)$ & 0.298 & 0.889 & 0.144 \\
\hline $\mathrm{Rb}$ & $0.2-0.8$ & $0.39 \pm 0.01(4 / 4)$ & $0.35 \pm 0.08(3 / 4)$ & $0.62 \pm 0.20(4 / 4)$ & $0.59 \pm 0.14(4 / 4)$ & 0.006 & 0.266 & 0.357 \\
\hline$S$ & $48.6-2330.9$ & $249.43 \pm 45.61(4 / 4)$ & $194.87 \pm 18.93(4 / 4)$ & $341.73 \pm 367.40(4 / 4)$ & $796.26 \pm 1075.4(4 / 4)$ & 0.746 & 0.971 & 0.815 \\
\hline $\mathrm{Zn}$ & $0.3-1.3$ & $0.77 \pm 0.10(4 / 4)$ & $0.58 \pm 0.07(4 / 4)$ & $0.44 \pm 0.08(4 / 4)$ & $0.91 \pm 0.46(3 / 4)$ & 0.233 & 0.872 & 0.377 \\
\hline \multicolumn{9}{|c|}{ Inorganic Anions } \\
\hline $\mathrm{Cl}^{-}$ & 2098.9-3925.2 & $2422.6 \pm 67.18(4 / 4)$ & $2545.2 \pm 219.52(4 / 4)$ & $2539.1 \pm 668.37(4 / 4)$ & $3048.1 \pm 593.46(4 / 4)$ & 0.236 & 0.151 & 0.918 \\
\hline $\mathrm{F}^{-}$ & $121.2-295.4$ & $245.14 \pm 28.32(4 / 4)$ & $245.81 \pm 35.64(4 / 4)$ & $195.70 \pm 58.43(4 / 4)$ & $213.64 \pm 2.98(4 / 4)$ & 0.058 & 0.514 & 0.773 \\
\hline $\mathrm{NO}^{3-}$ & $762.8-2581.9$ & $941.12 \pm 77.57(4 / 4)$ & $787.04 \pm 30.56(4 / 4)$ & $1488.7 \pm 376.20(4 / 4)$ & $1438.2 \pm 822.63(4 / 4)$ & 0.009 & 0.327 & 0.113 \\
\hline $\mathrm{PO}_{4}^{3-}$ & $741.8-1038.7$ & $927.47 \pm 104.85(4 / 4)$ & $813.42 \pm 17.03(4 / 4)$ & $789.21 \pm 60.03(4 / 4)$ & $788.06 \pm 30.53(4 / 4)$ & 0.021 & 0.104 & 0.537 \\
\hline $\mathrm{SO}_{4}^{2-}$ & $1470.2-3005.4$ & $1657.8 \pm 28.86(4 / 4)$ & $1620.5 \pm 14.80(4 / 4)$ & $1694.7 \pm 218.43(4 / 4)$ & $1970.4 \pm 722.29(4 / 4)$ & 0.370 & 0.629 & 0.513 \\
\hline
\end{tabular}




\subsection{Alpha and Beta Microbial Diversity}

Sequencing analysis resulted in a total of 50,757 raw reads. After removal of chimeras, unassigned, or mitochondrial reads, we ended with 48,595 good quality reads assigned to bacteria with a mean length of $333 \mathrm{bp}$. No chloroplast reads were detected in our samples. A total of 307 ASVs were identified for all treatments, with 58 ASVs being retained for alpha and beta diversity analysis after rarefying all data to the minimum number of reads obtained and singleton removal. The Scheirer-Ray-Hare test indicated significant differences $(p<0.05)$ for Shannon alpha-diversity index according to olive age $(\mathrm{H}>11.29, p<0.0008)$ with no significant differences $(p \geq 0.05)$ between olive genotypes $(\mathrm{H}<0.01, p>0.999)$ or its interaction with the age treatment $(\mathrm{H}<0.05, p>0.833)$. Richness alpha-diversity index showed no significant differences $(p \geq 0.05)$ according to plant age, genotype, or their interaction $(\mathrm{H}<1.10, p>0.293)$ (Figure S1).

Principal coordinate analysis of weighted UniFrac distances differentiated xylem bacterial communities mainly according to the plant age. Thus, there was a clear trend to group the bacterial communities along Axis 1, which explained $72.2 \%$ of the variation, mainly by the plant age, and then along Axis 2 , which explained $7.4 \%$ of the variation by olive plant genotype, being more affected in adult plants than in plantlets. Thus, ADONIS analysis supported these results and indicated a main significant effect of the plant age $\left(R^{2}=0.667, p<0.002\right)$, with no significant differences according to the olive genotype $\left(R^{2}=0.017, p=0.463\right)$, or their interaction $\left(R^{2}=0.030, p=0.254\right)$ (Figure 2).

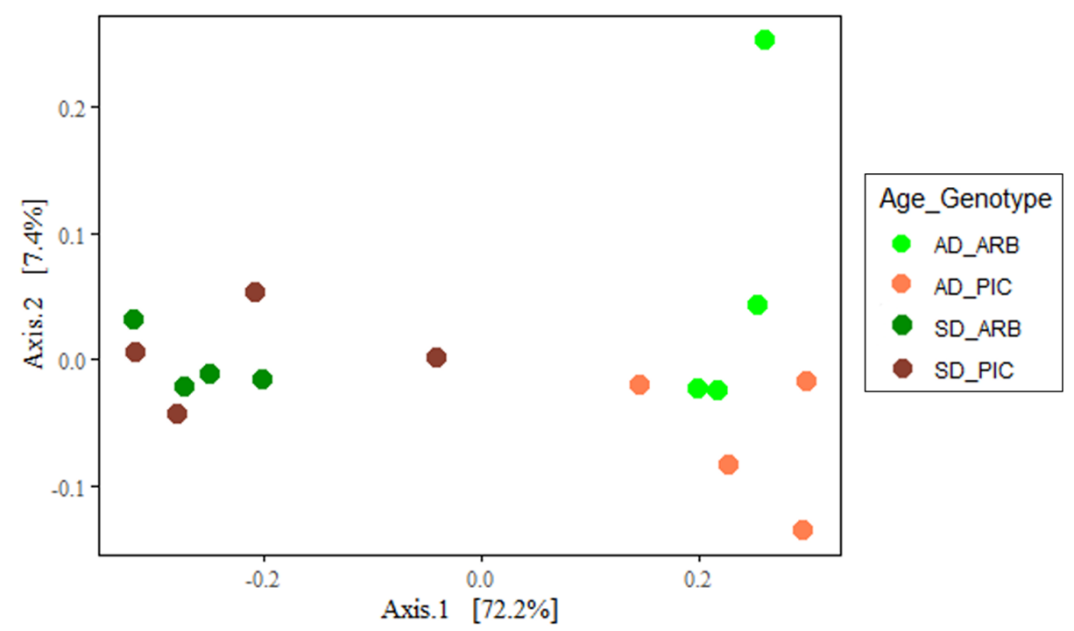

Figure 2. Principal coordinates plot of weighted UniFrac distances of bacterial communities, at ASV taxonomic level, in xylem sap of plantlets (SD) and adult (AD) olive trees of 'Picual' (PIC) and 'Arbequina' (ARB) genotypes.

\subsection{Composition and Abundance of Bacterial Communities in Olive Xylem Sap}

A total of 11 phyla, 19 classes, 70 orders, 104 families, 182 genera, and 307 ASVs were identified considering all treatments. At the genus level, a total of 121 genera formed the core microbiome of plantlets and adult plants, whereas 149 genera were shared between olive genotypes (Figure 3). In addition, a higher number of genera were found in adult and Picual plants (160 and 167, respectively) compared to those in plantlets and Arbequina genotype (143 and 164, respectively). On the other hand, unique genera were identified when analyzing the bacterial composition according to plant age or olive genotype. Thus, in adult plants, a total of nine unique genera were found in 'Arbequina' (three unidentified ASVs from the Erwiniaceae and 67-14 families and the Micrococcales order, Amnibacterium, Rhodoplanes, Bifidobacterium, Caedibacter, Methylibium and S5-A14a), while 10 genera were exclusive in 'Picual' (six unidentified ASVs from the Sphingomonadaceae, Finegoldia and Fimbriimonadaceae families and the _0319-6G20 order and two members of Class Alphaproteobacteria, Abiotrophia, Rubritepida, Mobiluncus, and Devosia). On the other hand, the number of unique genera was much lower in plantlets, with only one unique genus in 


\begin{abstract}
'Arbequina' (an unidentified ASV from the Phylum_Firmicutes), while three genera were exclusive to 'Picual' (Brachybacterium, Alloprevotella and 28-YEA-48) (Figure 3).

When analyzing all experimental treatments together Firmicutes was the phylum showing the highest relative abundance $(66.63 \%)$, followed by Proteobacteria $(20.56 \%)$ and Actinobacteriota (11.28\%) (Figure S2). However, these relative abundances varied within each treatment tested. Actinobacteria and Proteobacteria were more abundant in adult olive plants, with a proportion of $34.21 \%$ and $29.63 \%$, respectively, decreasing to $2.58 \%$ and $17.11 \%$ in plantlets. On the contrary, the relative percentage of Firmicutes increased from adult plants to plantlets $(34.01 \%$ to $79.00 \%)$. The relative abundance of xylem microbial communities remained similar regarding the olive genotype at the phylum taxonomic level.

At the genus level, the most abundant genera identified among all treatments were Anoxybacillus (51.94\%), Cutibacterium (6.89\%), Massilia (5.66\%), Pseudomonas (3.21\%), Paenibacillus (2.56\%), Exiguobacterium (2.43\%), Bradyrhizobium (2.18\%), Sphingomonas (1.45\%) and Brevibacillus (1.02\%). Anoxybacillus was the genus with the highest relative abundance, reaching maximum frequencies in olive plantlets (both in 'Arbequina' (64.93\%) and 'Picual' $(66.95 \%))$. A noticeably lower relative abundance of Cutibacterium was found in plantlets from both genotypes, with $0.99 \%$ in 'Arbequina' and $0.84 \%$ in 'Picual', respectively) as compared to adult trees that presented $23.42 \%$ in 'Arbequina' and $22.03 \%$ in 'Picual'. Moreover, the small proportion of Exiguobacterium found in adult trees of 'Arbequina' (3.31\%) compared to that of 'Picual' (13.22\%) and the higher relative abundance of Paenibacillus in plantlets of 'Arbequina' (4.37\%) as compared to 'Picual' (2.64\%) were remarkable.
\end{abstract}

\section{Age-Genotype}

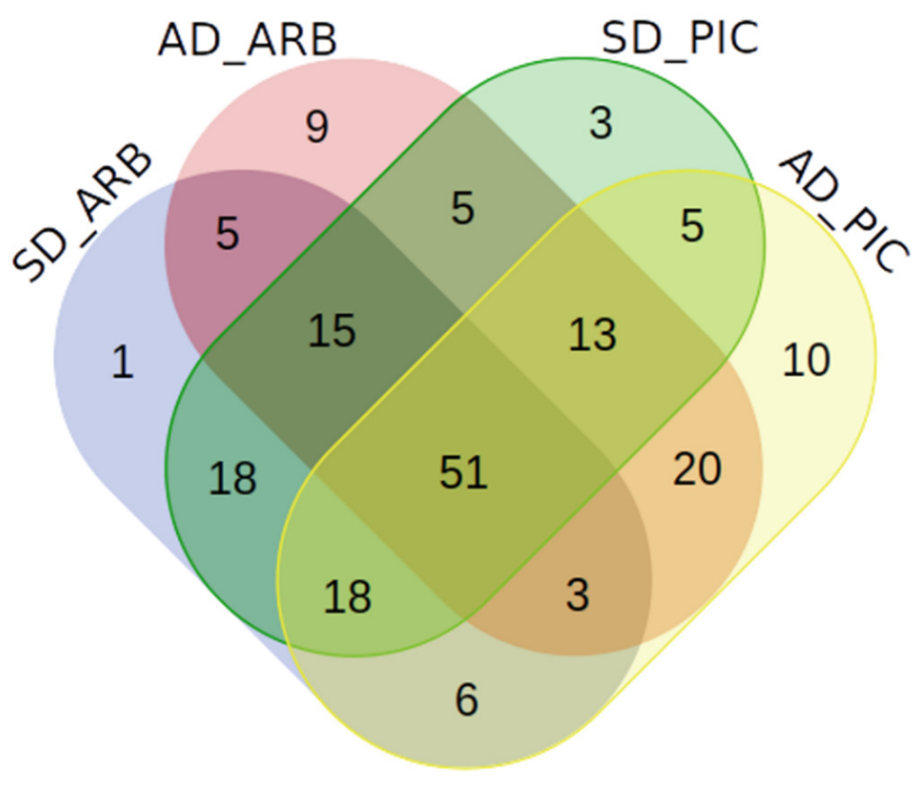

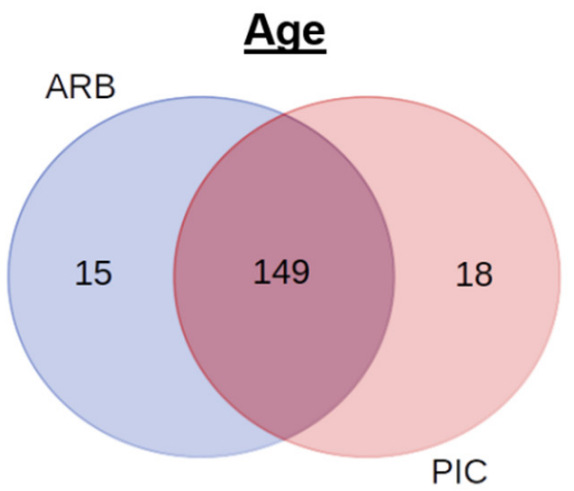

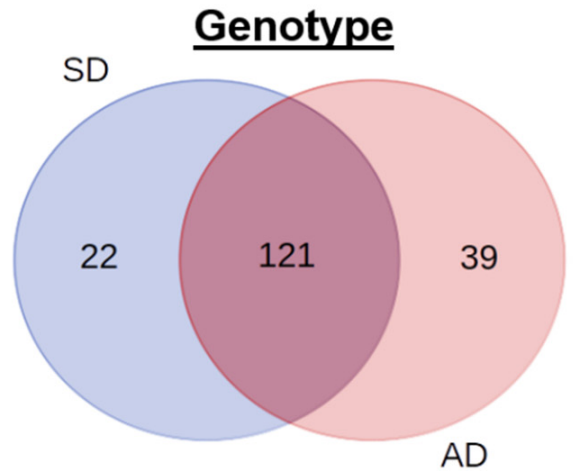

Figure 3. Prevalence Venn diagrams showing the unique and shared bacterial genera in olive xylem sap of plantlets (SD) and adult (AD) olive trees of 'Picual' (PIC) and 'Arbequina' (ARB) genotypes.

\title{
3.4. Effect of Olive Plant Age and Genotype in Xylem Sap Chemical and Microbial Composition
}

Analysis of variance (ANOVA) indicated the existence of significant differences $(p<0.05)$ on the levels of some metabolites according to the age of the plant including the sugars glucose, fructose, sucrose and mannitol and the osmolite choline that showed significantly $(p<0.037)$ higher values in adult trees as compared to plantlets for both olive genotypes (Table 1). Aspartic acid content showed significantly higher values $(p=0.0496)$ 
in 'Picual' plants than in 'Arbequina' plants, irrespective of plant age. Phenylalanine was not detected on adult trees of 'Arbequina' and showed similar values for the other three experimental combinations. Additionally, ethanol content was significantly higher $(p<0.037)$ in plantlets as compared to adult trees, but only in cv. Arbequina.

Concerning mineral elements and inorganic ions, the concentration of $\mathrm{B}$ and $\mathrm{PO}_{4}{ }^{3-}$ were significantly higher $(p<0.021)$ in adult trees than in plantlets, whereas $\mathrm{NO}^{3-}$ and $\mathrm{Rb}$ content showed the opposite behavior (Table 2). On the other hand, Na content was significantly ( $p=0.024)$ higher in 'Picual' than in 'Arbequina' plants for both plant ages and Fe showed the opposite behavior but only for adult trees $(p=0.086)$ (Table 2). Finally, Sr showed significant $(p<0.033)$ higher values for adult plants as compared to plantlets, except for 'Picual' where no differences existed between the two plant ages $(p=0.635)$.

Hierarchical clustering analyses using all chemical compounds and all identified bacterial ASVs separated xylem sap composition according to the olive plant age in first place, with a minor role of the olive cultivar (Supplementary Figure S3A,B). Similarly, PLSDA analysis of all metabolites, mineral elements, and inorganic ions were clearly distinct for xylem sap according to the plant age, and then, within them there was a trend to group the xylem samples according to the olive genotype ('Arbequina' and 'Picual'), with this effect being clearer for adult trees (Figure 4A). PLS-DA ranked the compounds using the variable importance in projection (VIP) scores at $p=0.05$, and showed that $\mathrm{Sr}, \mathrm{B}$, fructose, mannitol, Fe, sucrose, and glucose had the highest VIP scores, showing higher values for adult trees as compared to plantlets, with ethanol showing the opposite trend (Figure 4A). Additionally, the PLS-DA clearly discriminated 'Arbequina' and 'Picual' olive genotypes when separate analyses were performed for each plant age. Asparagine, glutamic acid, phenylalanine and aspartic acid were the compounds that showed higher VIP score values and reached lower concentrations in 'Arbequina' than in 'Picual' for adult trees. On the other hand, aspartic acid, ethanol, arginine and $\mathrm{Sr}$ were the most contributory VIP variables in the discrimination of both genotypes in the PLS-DA model for plantlets. Thus, all those compounds, with the only exception of ethanol, showed lower levels in 'Arbequina' than in 'Picual' plantlets (Figure 4B).

Focusing on the microbial communities, the PLS-DA models discriminated 'Arbequina' and 'Picual' olive genotypes when separate analyses were performed for each plant age although this discrimination was more evident in adult trees than in plantlets (Figure 5A). ASV17-Sporichthya and ASV411-Anoxybacillus were the bacteria that showed higher VIP score values and reached higher concentrations in 'Arbequina' than in 'Picual' for adult trees in contrast to ASV314-Exiguobacterium and ASV73-Cutibacterium that showed an opposite behavior. On the other hand, ASV115-Massilia, ASV371-Bacillaceae, ASV408Anoxybacillus, and ASV159-Pseudomonas were the most contributory VIP ASVs in the discrimination of both genotypes in the PLS-DA model for plantlets. Thus, ASV115Massilia and an uncultured ASV371-Bacillaceae showed higher levels in 'Arbequina' than in 'Picual', in contrast to ASV408-Anoxybacillus and ASV159-Pseudomonas which showed the opposite behavior (Figure 5B). 
A
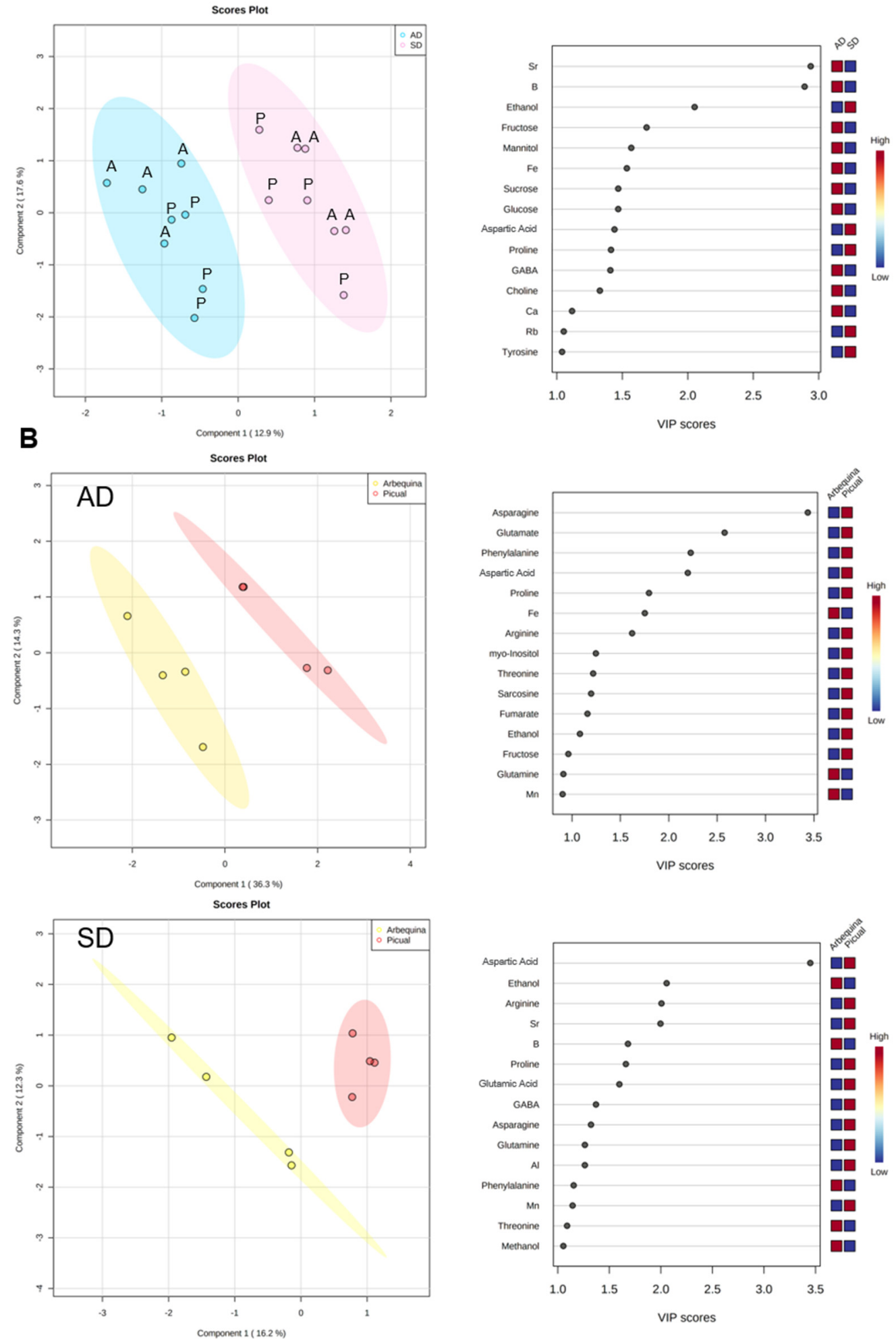

Figure 4. Partial least squares discriminant (PLS-DA) 2D score plot and loading importance in projection (VIP scores) in the first PLS-DA component of metabolomic and ionomic profile of olive xylem sap of plantlets (SD) and adult (AD) olive trees of 'Picual' (PIC) and 'Arbequina' (ARB) genotypes. (A) Combined analysis of all olive cultivars and plant age combinations. (B) Separate analysis by olive plant age. 
A
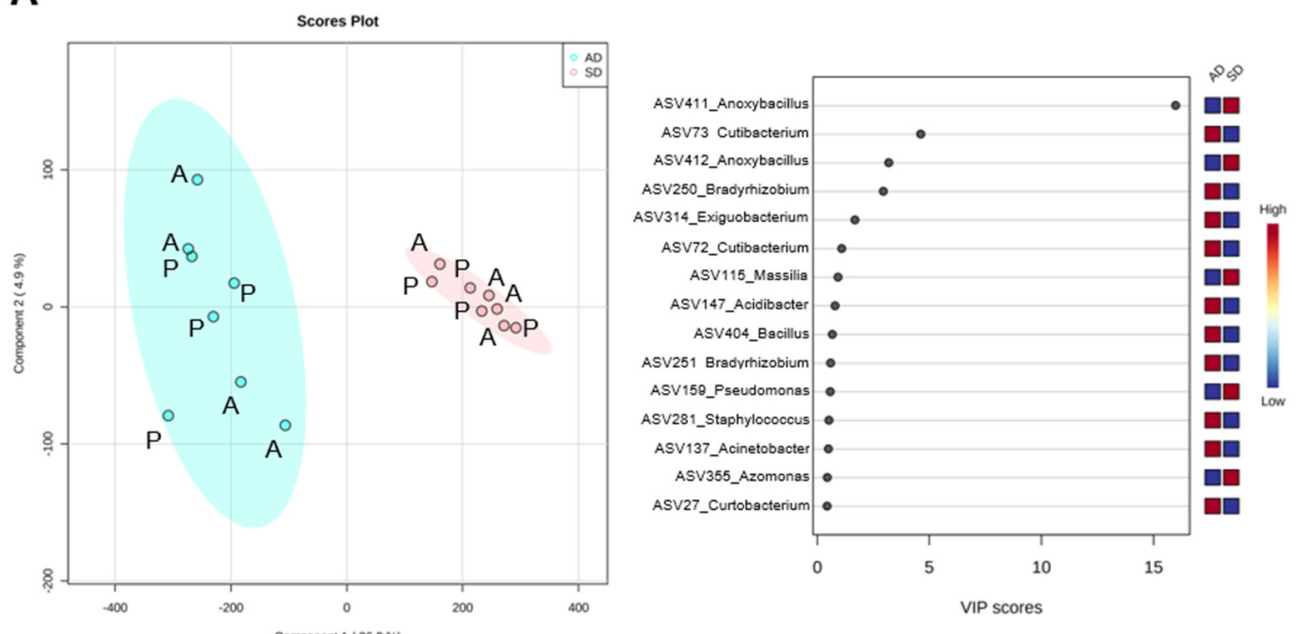

B
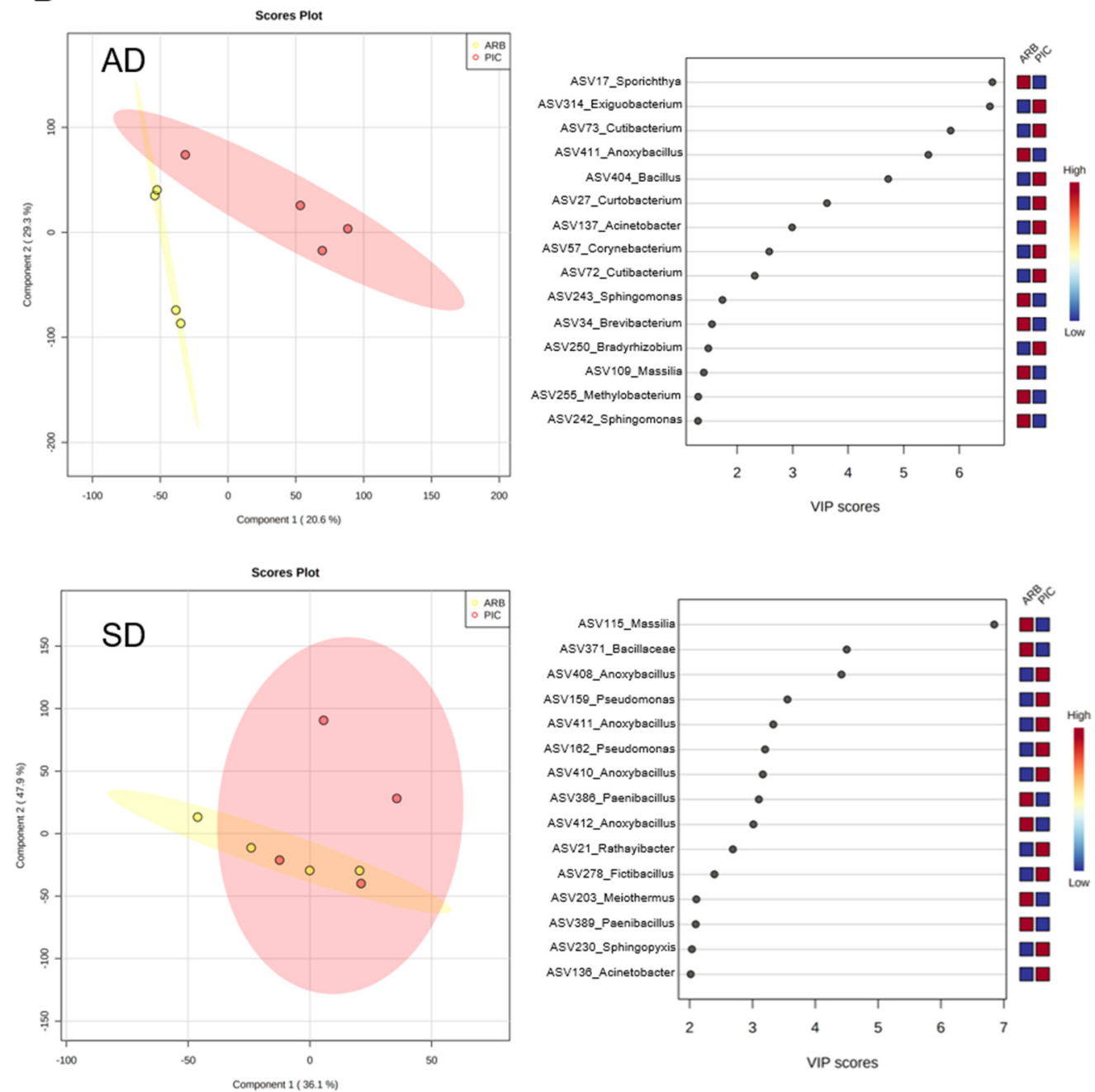

Figure 5. Partial least squares discriminant (PLS-DA) 2D score plot and loading importance in projection (VIP scores) in the first PLS-DA component of microbiome profile of olive xylem sap of plantlets (SD) and adult (AD) olive trees of 'Picual' (PIC) and 'Arbequina' (ARB) genotypes. (A) Combined analysis of all olive cultivars and plant age combinations. (B) Separate analysis by olive plant age.

NMDS analysis based on Bray-Curtis dissimilarity identified 9 significant variables associated with olive xylem sap by the envfit analysis. Sucrose was the metabolite showing the highest contribution $\left(R^{2}=0.72 ; p=0.001\right)$ to explain bacterial community composition 
followed by $\operatorname{Sr}\left(R^{2}=0.62 ; p=0.003\right)$, trigonelline $\left(R^{2}=0.61 ; p=0.009\right)$, mannitol $\left(R^{2}=0.50\right.$; $p=0.017)$ and $\mathrm{Rb}\left(R^{2}=0.48 ; p=0.022\right)$. Sarcosine, glucose, mannitol, sucrose, $\mathrm{Sr}, \mathrm{PO}_{4}{ }^{3-}, \mathrm{Fe}$, and trigonelline were more associated to adult trees, whereas $\mathrm{Rb}$ was mainly associated to the olive plantlets. According to olive genotype, the sugars glucose, mannitol and sucrose and the osmolyte sarcosine were strongly correlated with 'Arbequina' while the ions $\mathrm{Sr}$, $\mathrm{PO}_{4}{ }^{3-}, \mathrm{Fe}$, and $\mathrm{Rb}$ and the osmolyte trigonelline were correlated with 'Picual' (Figure 6).

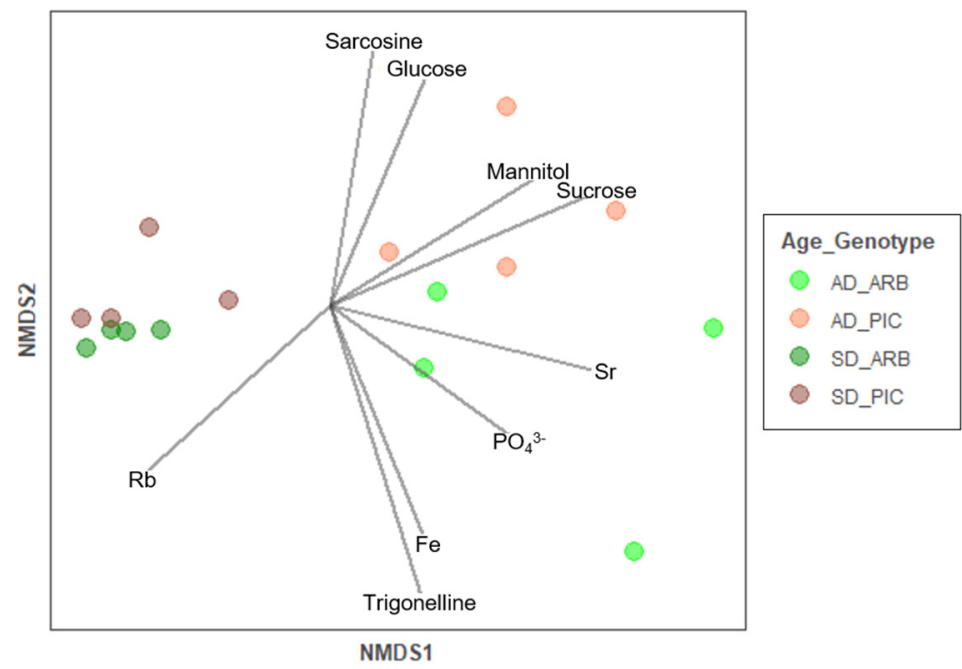

Figure 6. NMDS based on Bray-Curtis dissimilarity and environmental fitting test analysis (envfit) displaying significant chemical variables $(p<0.05)$ explaining bacterial ASV distribution in olive xylem sap of plantlets (SD) and adult (AD) olive trees of 'Picual' (PIC) and 'Arbequina' (ARB) genotypes.

\section{Discussion}

The results of this study reveal for the first time the effect of plant age and olive genotype on the differentiation of the chemical and microbial composition of olive xylem sap. These new insights regarding the metabolomic and ionomic profiles together with the microbiome composition of olive xylem sap provide new information for the characterization of the living environment for xylem-inhabiting olive endophytes which may result in a better understanding of the nutritional requirements for the growth of those microorganisms. Indeed, knowing the nutritional requirements of the xylem plant-associated microorganisms will enable to design more specific culture media for its in vitro cultivation and isolation and to understand some factors related to the biology and pathogenicity of emerging xylem-inhabiting pathogens, such as $V$. dahliae and $X$. fastidiosa that represent the major threats for olive growth and productivity worldwide.

Our results showed that olive xylem sap contains a wide variety of chemical compounds. Thus, we found a high level of sugars, which were the main metabolites present in olive xylem sap, followed by alcohols, amino acids, and organic acids. In fact, mean values displayed mannitol, ethanol, glutamine, and acetic acid as the principal compounds within each chemical group. These results are in line with the findings of several authors where mannitol was abundant in sap from maples [50] or glutamine was found to be the main amino acid in tomato, maize, and grapevine [16,28,51]. In addition, the role of these compounds in the plant kingdom has been widely reported. Thus, mannitol is known as an osmoregulatory, being synthesized by plants in response to dehydration conditions [52], and has a remarkable role in protecting plant cells against damage by reactive oxygen species (ROS) [53]. Furthermore, the presence of mannitol in our study is significantly correlated with bacteria composition in adult trees and it has been described as a key component in plant defense [54]. Otherwise, several works have studied the role of glutamine amino acid in the activation of defense responses of the plant against pathogens where the deficit of glutamine is linked to the inhibition of glutamine synthetase complex activating plant 
defense genes [55,56], or the antibacterial activity of acetic acid that supports flavonoid and lipid biosynthesis [57,58]. In relation to ions, $\mathrm{K}$ and $\mathrm{Cl}^{-}$were the element and inorganic anion more abundant, respectively. High levels of $\mathrm{K}$ were reported in grapevines [59] whose availability is determinant for proper plant growth [60].

Although, several authors have identified the chemical composition of xylem sap in different crops [26-30] overcoming the technical difficulties and labor-intensive task of sap extraction from xylem tissues avoiding cytosolic contamination has been a challenge. This explains why a considerable gap of knowledge on the effect of plant age and genotype on the chemical composition of the xylem sap exists. Thus, the influence of plant age and genotype on the chemical composition of xylem sap has been overlooked, as only few studies have reported this interaction in leaves and roots. Nevertheless, some metabolomic studies have determined the existence of some differentiation of chemical compound dynamics during different plant growth stages in potato [61], soybeans [62], ginseng [63], and others herbaceous plants $[64,65]$ that may have contributed to different biological activity of the plant, such as flowering period, or might be the result of variations on soil properties or environmental conditions [61,62]. Other studies have determined the effect of plant genotype on sap composition including birch trees [66], mango [67], maize [68] and grapevines [69]. Although there is no systematic analysis of how genotype influences plant metabolome and ionome, some predictions address these differences depending on the organism considered, the analytical technique used, the tissue sampled and, most significantly, the interaction of the genotype with the environment due to the compensatory role of metabolites to maintain metabolic homeostasis through the genetic adaptation to environmental stress [70]. Hence, this work aimed to remediate the lack of information in olive concerning its xylem sap composition and relate this fact with the structure and composition of microbial populations to generate new insights that may be useful in future research by different disciplines including physiology, microbial ecology and plant pathology, among others. Our results suggested that the metabolome, ionome, and microbiome profiles of olive xylem sap varied mainly according to host plant age with the olive genotype playing a secondary role. These differential results may be due not only to the juvenile stage of the plantlets, but likely to the different fertilization regimens that each type of plant received during its entire life.

For olive in particular, some works have addressed the fruit metabolome from 'Leccino' and 'Frantoio' cultivars [71] or the variation of metabolites composition among different olive tissues including leaves and fruits [72]. However, most of the research has focused on the olive oil metabolome, e.g., [73-75]. To the best of our knowledge, only two works have studied the xylem sap composition based on the use of liquid chromatography (UHPLC) coupled to a hybrid quadrupole time-of-flight mass spectrometer (QTOF-MS) [30] or the use of gas chromatography mass spectrometry (GC-MS) [76]. Our results were obtained using NMR and ICP-OES, which, although less sensitive than mass spectrometry, have been shown to provide powerful insights for high-throughput metabolomics applications, detecting a wide range of metabolites in a quantitative manner [77,78]. QTOF-MS provided to Sofo et al. [30] the wide discrimination of xylem sap secondary metabolism, but only a few primary metabolites including some amino acids (leucine, isoleucine, tyrosine, glutamic acid and arginine) and organic acids (fumaric and maleic acids) were detected in contrast to our results that involved the discrimination of the primary metabolism of xylem sap supplying five organic acids, 15 amino acids, and five sugars, among other molecules. Moreover, Fausto et al. [76] recently annotated a wide diversity of metabolites in olive involved in the primary metabolism (amino acids, sugars, alcohols) that are in accordance with our results. Furthermore, as a point of difference, our work also provided information on the main mineral elements and inorganic anions present in the olive xylem sap.

Our NGS results with olive xylem sap indicated the presence of endophytic bacteria mainly from the phyla Firmicutes, Proteobacteria, and Actinobacteriota while the bacterial genera detected at highest proportions were, in this order, Anoxybacillus, Cutibacterium, Massilia, and Pseudomonas. Interestingly Anoxybacillus and Pseudomonas have also been identified in 
olive xylem in other works in which olive trees of different ages, belonging to different cultivars or growing under different environments, were evaluated [30,32,33,36,40,79], which strengthens the hypothesis that those genera may represent keystone olive xylem bacteria [33]. The beneficial functions of Pseudomonas spp. in plants have been widely reported for several crops, including olive [80-82]. Massilia has been described as a bacterium exerting plant growth promotion and in vitro antagonism activities [83]. However, little is known about the role of the genus Cutibacterium as a component of plant microbiome.

In this study, the differences found on xylem sap chemical and microbial composition between both olive cultivars were of particular interest, especially those found in adult trees where the effect of the genotype was more noticeable than in young plantlets, even though both genotypes have received same agronomic practices and grew in the same field for more than 10 years. This differential composition of xylem sap deserves further research by including additional olive genotypes, since they differ significantly in their resistance response to Verticillium wilt caused by $V$. dahliae $[84,85]$ and X. fastidiosa $[6,86,87]$. Moreover, some authors found that disease severity in olive cultivars susceptible to $V$. dahliae decreases with host age $[84,88]$ although the metabolome and microbiome composition of xylem sap in these adult trees remain an unexplored field to date. Interestingly, several authors have studied the effect of both vascular pathogens, X. fastidiosa [86,89-91] and V. dahliae [1,92] in the metabolomic and ionomic profiles of olive trees where the identification of specific chemical compounds in stems, leaves, and fruits has been referred to as potentially being involved in the defense mechanisms of the host plant against these pathogens. Similarly, differences on xylem sap microbial composition have been associated to the differential resistance observed in different olive genotypes to those vascular pathogens $[40,87]$.

This present study is the first to date that describes the metabolomic, ionomic and microbial composition of a perennial crop and identifies specific differences in xylem sap composition upon contrasting stages of plant age and olive genotypes. Being aware of our limitations due to few samples analyzed and the exploration of only two olive genotypes, we observed a major influence of olive plant age in xylem sap chemical and bacterial composition, with a clear differentiation between the plantlets from the adult trees while the effect of the genotype was more evident on adult trees. These results have provided new knowledge concerning the chemical composition of olive xylem sap and its effect in shaping bacterial community structure that will be particularly useful for the characterization of the nutritional requirements of olive xylem-inhabiting microorganisms. Finally, our results will also help to design more specific culture media, facilitating the isolation and in vitro growth of the xylem-inhabiting olive microbiome [32], which can serve as potential biological control agents against vascular pathogens in olive.

Supplementary Materials: The following are available online at https:/ / www.mdpi.com/article/10 .3390/agronomy11061179/s1, Figure S1: Boxplots of Richness and Shannon diversity indices at ASV taxonomic level in olive xylem sap of plantlets (SD) and adult (AD) olive trees of 'Picual' (PIC) and 'Arbequina' (ARB) genotypes. Boxes represent the interquartile range, while the horizontal line inside the box defines the median and whiskers represent the lowest and highest values of four values for each treatment combination. The Scheirer-Ray-Hare test at $p<0.05$ was used to find significance differences according to age, genotype and its interaction, Figure S2: Bar plots showing the relative bacterial abundance taxa at phylum (left-panel) and genera (right-panel) level present in olive xylem sap of plantlets (SD) and adult (AD) olive trees of 'Picual' (PIC) and 'Arbequina' (ARB) genotypes, Figure S3: Hierarchical clustering and heatmap of metabolomic and ionomic (left) and microbial (right) profiles of olive xylem sap of plantlets (SD) and adult (AD) olive trees of 'Picual' (PIC) and 'Arbequina' (ARB) genotypes.

Author Contributions: M.A.-M. and B.B.L.: conceived research and wrote the manuscript; M.A.-M., J.A.N.-C. and B.B.L.: performed statistical analyses; M.A.-M., C.H. and M.M.-B.: prepared materials and equipment and performed the experiments. L.D.L.F. and J.A.N.-C.: contributed to reviewing the manuscript and interpreting results. All authors have read and agreed to the published version of the manuscript. 
Funding: This research was funded by projects AGL2016-75606-R (Programa Estatal de I + D Orientado a los Retos de la Sociedad from the Spanish Government and the Spanish State Research Agency and FEDER-EU) and XF-ACTORS (Xylella fastidiosa Active Containment Through a MultidisciplinaryOriented Research Strategy; grant 727987 from the European Union's Horizon 2020 Framework Research Programme). M.A.-M. is a recipient of a research fellowship BES-2017-082361 from the Spanish Ministry of Economy and Competitiveness.

Institutional Review Board Statement: Not applicable.

Informed Consent Statement: Not applicable.

Conflicts of Interest: The authors declare no conflict of interest. The funders had no role in the design of the study; in the collection, analyses, or interpretation of data; in the writing of the manuscript, or in the decision to publish the results.

\section{References}

1. Landa, B.B.; Pérez, A.G.; Luaces, P.; Montes-Borrego, M.; Navas-Cortés, J.A.; Sanz, C. Insights into the Effect of Verticillium dahliae Defoliating-Pathotype Infection on the Content of Phenolic and Volatile Compounds Related to the Sensory Properties of Virgin Olive Oil. Front. Plant Sci. 2019, 10, 232. [CrossRef]

2. Allen, H.D.; Randall, R.E.; Amable, G.S.; Devereux, B.J. The impact of changing olive cultivation practices on the ground flora of olive groves in the Messara and Psiloritis regions, Crete, Greece. Land Degrad. Dev. 2006, 17, 249-273. [CrossRef]

3. Gómez, A.J.; Infante-Amate, J.; De Molina, G.M.; Vanwalleghem, T.; Taguas, V.E.; Lorite, I. Olive Cultivation, its Impact on Soil Erosion and its Progression into Yield Impacts in Southern Spain in the Past as a Key to a Future of Increasing Climate Uncertainty. Agriculture 2014, 4, 170-198. [CrossRef]

4. Tscheulin, T.; Neokosmidis, L.; Petanidou, T.; Settele, J. Influence of landscape context on the abundance and diversity of bees in Mediterranean olive groves. Bull. Èntomol. Res. 2011, 101, 557-564. [CrossRef] [PubMed]

5. Jiménez-Díaz, R.M.; Cirulli, M.; Bubici, G.; Jiménez-Gasco, M.D.M.; Antoniou, P.P.; Tjamos, E.C. Verticillium Wilt, A Major Threat to Olive Production: Current Status and Future Prospects for its Management. Plant Dis. 2012, 96, 304-329. [CrossRef] [PubMed]

6. Saponari, M.; Giampetruzzi, A.; Loconsole, G.; Boscia, D.; Saldarelli, P. Xylella fastidiosa in Olive in Apulia: Where We Stand. Phytopathology 2019, 109, 175-186. [CrossRef] [PubMed]

7. White, P.J. Chapter 3-Long-distance Transport in the Xylem and Phloem. In Marschner's Mineral Nutrition of Higher Plants; Third, E., Ed.; Academic Press: San Diego, CA, USA, 2012; pp. 49-70, ISBN 978-0-12-384905-2.

8. De Boer, A.H.; Volkov, V. Logistics of water and salt transport through the plant: Structure and functioning of the xylem. Plant Cell Environ. 2003, 26, 87-101. [CrossRef]

9. Schurr, U. Xylem sap sampling-New approaches to an old topic. Trends Plant Sci. 1998, 3, 293-298. [CrossRef]

10. Horsfield, D. Relationships between feeding of Philaenus spumarius (L.) and the amino acid concentration in the xylem sap. Ecol. Èntomol. 1977, 2, 259-266. [CrossRef]

11. Sauter, J.J. Seasonal Variation of Amino Acids and Amides in the Xylem Sap of Salix. Z. Pflanzenphysiol. 1981, 101, 399-411. [CrossRef]

12. Schurr, U.; Schulze, E.-D. The concentration of xylem sap constituents in root exudate, and in sap from intact, transpiring castor bean plants (Ricinus communis L.). Plant Cell Environ. 1995, 18, 409-420. [CrossRef]

13. Tatar, E.; Mihucz, V.; Varga, A.; Zaray, G.; Fodor, F. Determination of Organic Acids in Xylem Sap of Cucumber: Effect of Lead Contamination. Microchem. J. 1998, 58, 306-314. [CrossRef]

14. Garcia, N.F.; Hernandez, M.; Casado-Vela, J.; Bru, R.; Elortza, F.; Hedden, P.; Olmos, E. Changes to the proteome and targeted metabolites of xylem sap in Brassica oleracea in response to salt stress. Plant Cell Environ. 2011, 34, 821-836. [CrossRef]

15. Krishnan, H.B.; Natarajan, S.S.; Bennett, J.O.; Sicher, R.C. Protein and metabolite composition of xylem sap from field-grown soybeans (Glycine max). Planta 2011, 233, 921-931. [CrossRef]

16. Alvarez, S.; Marsh, E.L.; Schroeder, S.G.; Schachtman, D.P. Metabolomic and proteomic changes in the xylem sap of maize under drought. Plant Cell Environ. 2008, 31, 325-340. [CrossRef] [PubMed]

17. Gollan, T.; Schurr, U.; Schulze, E.-D. Stomatal response to drying soil in relation to changes in the xylem sap composition of Helianthus annuus. I. The concentration of cations, anions, amino acids in, and pH of, the xylem sap. Plant Cell Environ. 1992, 15, 551-559. [CrossRef]

18. Ferguson, A.R. Xylem Sap from Actinidia chinensis: Apparent Differences in Sap Composition Arising from the Method of Collection. Ann. Bot. 1980, 46, 791-801. [CrossRef]

19. Dambrine, E.; Martin, F.; Carisey, N.; Granier, A.; Hällgren, J.-E.; Bishop, K. Xylem sap composition: A tool for investigating mineral uptake and cycling in adult spruce. Plant Soil 1995, 168, 233-241. [CrossRef]

20. Jones, O.P. Effects of Rootstocks and Interstocks on the Xylem Sap Composition in Apple Trees: Effects on Nitrogen, Phosphorus, and Potassium Content. Ann. Bot. 1971, 35, 825-836. [CrossRef]

21. Subramanian, S.; Cho, U.-H.; Keyes, C.; Yu, O. Distinct changes in soybean xylem sap proteome in response to pathogenic and symbiotic microbe interactions. BMC Plant Biol. 2009, 9, 119. [CrossRef] 
22. Wallis, C.M.; Chen, J. Grapevine Phenolic Compounds in Xylem Sap and Tissues Are Significantly Altered During Infection by Xylella fastidiosa. Phytopathology 2012, 102, 816-826. [CrossRef] [PubMed]

23. Thomas, R.J.; Feller, U.; Erismann, K.H. The Effect of Different Inorganic Nitrogen Sources and Plant Age on the Composition of Bleeding Sap of Phaseolus Vulgaris. New Phytol. 1979, 82, 657-669. [CrossRef]

24. Tromp, J. Seasonal Variations in the Composition of Xylem Sap of Apple with Respect to K, Ca, Mg, and N. Z. Pflanzenphysiol. 1979, 94, 189-194. [CrossRef]

25. Ferguson, A.R.; Eiseman, J.A.; Leonard, J.A. Xylem Sap from Actinidia chinensis: Seasonal Changes in Composition. Ann. Bot. 1983, 51, 823-833. [CrossRef]

26. Rennenberg, H.; Schupp, R.; Glavac, V.; Jochheim, H. Xylem sap composition of beech (Fagus sylvatica L.) trees: Seasonal changes in the axial distribution of sulfur compounds. Tree Physiol. 1994, 14, 541-548. [CrossRef]

27. Rellán-Álvarez, R.; El-Jendoubi, H.; Wohlgemuth, G.; Abadia, A.; Fiehn, O.; Abadía, J.; Álvarez-Fernández, A. Metabolite profile changes in xylem sap and leaf extracts of strategy I plants in response to iron deficiency and resupply. Front. Plant Sci. 2011, 2, 66. [CrossRef]

28. Lima, M.R.M.; Machado, A.F.; Gubler, W.D. Metabolomic Study of Chardonnay Grapevines Double Stressed with Esca-Associated Fungi and Drought. Phytopathology 2017, 107, 669-680. [CrossRef]

29. Gallinger, J.; Gross, J. Unraveling the Host Plant Alternation of Cacopsylla pruni-Adults but Not Nymphs Can Survive on Conifers Due to Phloem/Xylem Composition. Front. Plant Sci. 2018, 9, 484. [CrossRef]

30. Sofo, A.; Fausto, C.; Mininni, A.N.; Dichio, B.; Lucini, L. Soil management type differentially modulates the metabolomic profile of olive xylem sap. Plant Physiol. Biochem. 2019, 139, 707-714. [CrossRef]

31. McCully, M.E. Niches for bacterial endophytes in crop plants: A plant biologist's view. Funct. Plant Biol. 2001, 28, 983. [CrossRef]

32. Anguita-Maeso, M.; Olivares-García, C.; Haro, C.; Imperial, J.; Navas-Cortés, J.A.; Landa, B.B. Culture-Dependent and CultureIndependent Characterization of the Olive Xylem Microbiota: Effect of Sap Extraction Methods. Front. Plant Sci. 2020, 10, 1708. [CrossRef]

33. Anguita-Maeso, M.; Trapero-Casas, J.L.; Olivares-García, C.; Ruano-Rosa, D.; Palomo-Ríos, E.; Jiménez-Díaz, R.M.; Navas-Cortés, J.A.; Landa, B.B. Verticillium dahliae Inoculation and in vitro Propagation Modify the Xylem Microbiome and Disease Reaction to Verticillium Wilt in a Wild Olive Genotype. Front. Plant Sci. 2021, 12, 250. [CrossRef] [PubMed]

34. Haro, C.; Anguita-Maeso, M.; Metsis, M.; Navas-Cortés, J.A.; Landa, B.B. Evaluation of Established Methods for DNA Extraction and Primer Pairs Targeting 16S rRNA Gene for Bacterial Microbiota Profiling of Olive Xylem Sap. Front. Plant Sci. 2021, 12, 296. [CrossRef]

35. Deyett, E.; Roper, M.C.; Ruegger, P.; Yang, J.-I.; Borneman, J.; Rolshausen, P.E. Microbial Landscape of the Grapevine Endosphere in the Context of Pierce's Disease. Phytobiomes J. 2017, 1, 138-149. [CrossRef]

36. Fausto, C.; Mininni, A.N.; Sofo, A.; Crecchio, C.; Scagliola, M.; Dichio, B.; Xiloyannis, C. Olive orchard microbiome: Characterisation of bacterial communities in soil-plant compartments and their comparison between sustainable and conventional soil management systems. Plant Ecol. Divers. 2018, 11, 597-610. [CrossRef]

37. Deyett, E.; Rolshausen, P.E. Temporal Dynamics of the Sap Microbiome of Grapevine Under High Pierce's Disease Pressure. Front. Plant Sci. 2019, 10, 1246. [CrossRef] [PubMed]

38. Zicca, S.; De Bellis, P.; Masiello, M.; Saponari, M.; Saldarelli, P.; Boscia, D.; Sisto, A. Antagonistic activity of olive endophytic bacteria and of Bacillus spp. strains against Xylella fastidiosa. Microbiol. Res. 2020, 236, 126467. [CrossRef] [PubMed]

39. Hong, C.E.; Park, J.M. Endophytic bacteria as biocontrol agents against plant pathogens: Current state-of-the-art. Plant Biotechnol. Rep. 2016, 10, 353-357. [CrossRef]

40. Giampetruzzi, A.; Baptista, P.; Morelli, M.; Cameirão, C.; Neto, T.L.; Costa, D.; D’Attoma, G.; Kubaa, R.A.; Altamura, G.; Saponari, M.; et al. Differences in the Endophytic Microbiome of Olive Cultivars Infected by Xylella Fastidiosa across Seasons. Pathogens 2020, 9, 723. [CrossRef]

41. Barranco, D. Varieties and Rootstocks. In Olive Grow; Barranco, D., Fernández, E.-R., Escobar, R., Rallo, L., Eds.; Junta de Andalucía/Mundi Prensa/RIRDC/AOA: Pendle Hill, Australia, 2010.

42. de la Rosa, G.; Peralta-Videa, J.R.; Montes, M.; Parsons, J.G.; Cano-Aguilera, I.; Gardea-Torresdey, J.L. Cadmium uptake and translocation in tumbleweed (Salsola kali), a potential Cd-hyperaccumulator desert plant species: ICP/OES and XAS studies. Chemosphere 2004, 55, 1159-1168. [CrossRef]

43. Akhtar, S.S.; Andersen, M.N.; Liu, F. Biochar Mitigates Salinity Stress in Potato. J. Agron. Crop. Sci. 2015, 201, 368-378. [CrossRef]

44. Kassambara, A. Rstatix: Pipe-Friendly Framework for Basic Statistical Tests. R Package Version 0.4.0. 2020. Available online: https:/ / cran.r-project.org/web/packages/rstatix/index.html (accessed on 1 March 2021).

45. Fox, J.; Weisberg, S. An R Companion to Applied Regression, 3rd ed.; Sage: Thousand Oaks, CA, USA, 2019. Available online: https://socialsciences.mcmaster.ca/jfox/Books/Companion/ (accessed on 1 March 2021).

46. Lee, L.C.; Liong, C.-Y.; Jemain, A.A. Partial least squares-discriminant analysis (PLS-DA) for classification of high-dimensional (HD) data: A review of contemporary practice strategies and knowledge gaps. Analyst 2018, 143, 3526-3539. [CrossRef]

47. Chong, J.; Wishart, D.S.; Xia, J. Using MetaboAnalyst 4.0 for Comprehensive and Integrative Metabolomics Data Analysis. Curr. Protoc. Bioinform. 2019, 68, e86. [CrossRef]

48. Callahan, B.J.; Mcmurdie, P.J.; Rosen, M.J.; Han, A.W.; Johnson, A.J.A.; Holmes, S.P. DADA2: High-resolution sample inference from Illumina amplicon data. Nat. Methods 2016, 13, 581-583. [CrossRef] [PubMed] 
49. Mangiafico, S. Rcompanion: Functions to Support Extension Education Program Evaluation. R Package Version 2.3.25. Available online: https: / /CRAN.R-project.org/package=rcompanion (accessed on 3 May 2021).

50. Garcia, E.J.; McDowell, T.; Ketola, C.; Jennings, M.; Miller, J.D.; Renaud, J.B. Metabolomics reveals chemical changes in Acer saccharum sap over a maple syrup production season. PLoS ONE 2020, 15, e0235787. [CrossRef] [PubMed]

51. Sung, J.; Sonn, Y.; Lee, Y.; Kang, S.; Ha, S.; Krishnan, H.B.; Oh, T.-K. Compositional changes of selected amino acids, organic acids, and soluble sugars in the xylem sap of N, P, or K-deficient tomato plants. J. Plant Nutr. Soil Sci. 2015, 178, 792-797. [CrossRef]

52. Hare, P.D.; Cress, W.A.; Van Staden, J. Dissecting the roles of osmolyte accumulation during stress. Plant Cell Environ. 1998, 21, 535-553. [CrossRef]

53. Patel, T.K.; Williamson, J.D. Mannitol in Plants, Fungi, and Plant-Fungal Interactions. Trends Plant Sci. 2016, $21,486-497$. [CrossRef] [PubMed]

54. Jlilat, A.; Ragone, R.; Gualano, S.; Santoro, F.; Gallo, V.; Varvaro, L.; Mastrorilli, P.; Saponari, M.; Nigro, F.; D’Onghia, A.M. A non-targeted metabolomics study on Xylella fastidiosa infected olive plants grown under controlled conditions. Sci. Rep. 2021, 11, 1-11. [CrossRef]

55. Huang, H.; Thu, T.N.T.; He, X.; Gravot, A.; Bernillon, S.; Ballini, E.; Morel, J.-B. Increase of Fungal Pathogenicity and Role of Plant Glutamine in Nitrogen-Induced Susceptibility (NIS) To Rice Blast. Front. Plant Sci. 2017, 8, 265. [CrossRef]

56. Seabra, A.R.; Carvalho, H. Inhibition of glutamine synthetase leads to a fast transcriptional activation of defense responses in root nodules. Model Legume Medicago Truncatula 2019, 665-673. [CrossRef]

57. Wei, J.; Wang, S.; Pei, D.; Qu, L.; Liangjing, Q.; Chen, J.; Di, D.; Gao, K. Antibacterial Activity of Hydroxytyrosol Acetate from Olive Leaves (Olea Europaea L.). Nat. Prod. Res. 2018, 32, 1967-1970. [CrossRef]

58. De Souza, L.P.; Garbowicz, K.; Brotman, Y.; Tohge, T.; Fernie, A.R. The Acetate Pathway Supports Flavonoid and Lipid Biosynthesis in Arabidopsis. Plant Physiol. 2020, 182, 857-869. [CrossRef]

59. Putra, D.P.; Botton, B. Organic and inorganic compounds of xylem exudates from five woody plants at the stage of bud breaking. J. Plant Physiol. 1998, 153, 670-676. [CrossRef]

60. Xu, X.; Du, X.; Wang, F.; Sha, J.; Chen, Q.; Tian, G.; Zhu, Z.; Ge, S.; Jiang, Y. Effects of Potassium Levels on Plant Growth, Accumulation and Distribution of Carbon, and Nitrate Metabolism in Apple Dwarf Rootstock Seedlings. Front. Plant Sci. 2020, 11, 904. [CrossRef] [PubMed]

61. Puzanskiy, R.K.; Yemelyanov, V.V.; Shavarda, A.L.; Gavrilenko, T.A.; Shishova, M.F. Age- and Organ-Specific Differences of Potato (Solanum phureja) Plants Metabolome. Russ. J. Plant Physiol. 2018, 65, 813-823. [CrossRef]

62. Yun, D.-Y.; Kang, Y.-G.; Kim, E.-H.; Kim, M.; Park, N.-H.; Choi, H.-T.; Go, G.H.; Lee, J.H.; Park, J.S.; Hong, Y.-S. Metabolomics approach for understanding geographical dependence of soybean leaf metabolome. Food Res. Int. 2018, 106, 842-852. [CrossRef] [PubMed]

63. Kim, Y.-J.; Joo, S.C.; Shi, J.; Hu, C.; Quan, S.; Hu, J.; Sukweenadhi, J.; Mohanan, P.; Yang, D.-C.; Zhang, D. Metabolic dynamics and physiological adaptation of Panax ginseng during development. Plant Cell Rep. 2017, 37, 393-410. [CrossRef] [PubMed]

64. Lawal, U.; Mediani, A.; Maulidiani, H.; Shaari, K.; Ismail, I.S.; Khatib, A.; Abas, F. Metabolite profiling of Ipomoea aquatica at different growth stages in correlation to the antioxidant and $\alpha$-glucosidase inhibitory activities elucidated by $1 \mathrm{H}$ NMR-based metabolomics. Sci. Hortic. 2015, 192, 400-408. [CrossRef]

65. Zheng, L.; Wang, M.; Ibarra-Estrada, E.; Wu, C.; Wilson, E.G.; Verpoorte, R.; Klinkhamer, P.G.L.; Choi, Y.H. Investigation of Chemomarkers of Astragali Radix of Different Ages and Geographical Origin by NMR Profiling. Molecules 2015, 20, 3389-3405. [CrossRef] [PubMed]

66. Ossipov, V.; Ossipova, S.; Bykov, V.; Oksanen, E.; Koricheva, J.; Haukioja, E. Application of metabolomics to genotype and phenotype discrimination of birch trees grown in a long-term open-field experiment. Metabolomics 2007, 4, 39-51. [CrossRef]

67. Tan, L.; Jin, Z.; Ge, Y.; Nadeem, H.; Cheng, Z.; Azeem, F.; Zhan, R. Comprehensive ESI-Q TRAP-MS/MS based characterization of metabolome of two mango (Mangifera indica L) cultivars from China. Sci. Rep. 2020, 10, 20017. [CrossRef] [PubMed]

68. Vasmatkar, P.; Kaur, K.; Pannu, P.; Kaur, G.; Kaur, H. Unraveling the metabolite signatures of maize genotypes showing differential response towards southern corn leaf blight by 1 H-NMR and FTIR spectroscopy. Physiol. Mol. Plant Pathol. 2019, 108, 101441. [CrossRef]

69. Billet, K.; Houillé, B.; De Bernonville, T.D.; Besseau, S.; Oudin, A.; Courdavault, V.; Delanoue, G.; Guérin, L.; Clastre, M.; GiglioliGuivarc'H, N.; et al. Field-Based Metabolomics of Vitis vinifera L. Stems Provides New Insights for Genotype Discrimination and Polyphenol Metabolism Structuring. Front. Plant Sci. 2018, 9, 798. [CrossRef] [PubMed]

70. Bundy, J.; Davey, M.P.; Viant, M.R. Environmental metabolomics: A critical review and future perspectives. Metabolomics 2009, 5, 3-21. [CrossRef]

71. Rosati, A.; Cafiero, C.; Paoletti, A.; Alfei, B.; Caporali, S.; Casciani, L.; Valentini, M. Effect of agronomical practices on carpology, fruit and oil composition, and oil sensory properties, in olive (Olea europaea L.). Food Chem. 2014, 159, 236-243. [CrossRef] [PubMed]

72. Guodong, R.; Xiaoxia, L.; Weiwei, Z.; Wenjun, W.; Jianguo, Z. Metabolomics reveals variation and correlation among different tissues of olive (Olea europaea L.). Biol. Open 2017, 6, 1317-1323. [CrossRef]

73. Merchak, N.; El Bacha, E.; Khouzam, R.B.; Rizk, T.; Akoka, S.; Bejjani, J. Geoclimatic, morphological, and temporal effects on Lebanese olive oils composition and classification: A 1H NMR metabolomic study. Food Chem. 2017, 217, 379-388. [CrossRef] 
74. Rongai, D.; Sabatini, N.; Del Coco, L.; Perri, E.; Del Re, P.; Simone, N.; Marchegiani, D.; Fanizzi, F.P. 1H NMR and Multivariate Analysis for Geographic Characterization of Commercial Extra Virgin Olive Oil: A Possible Correlation with Climate Data. Foods 2017, 6, 96. [CrossRef]

75. Culeddu, N.; Chessa, M.; Bandino, G.; Sedda, P.; Zurru, R.; Anedda, R.; Motroni, A.; Molinu, M.G.; Dettori, S.; Santona, M. Classification of Monovarietal Sardinian Extra Virgin Olive Oils by 1 H NMR Metabolomic. Eur. J. Lipid Sci. Technol. 2017, 119, 1700035. [CrossRef]

76. Fausto, C.; Araniti, F.; Mininni, A.N.; Crecchio, C.; Scagliola, M.; Bleve, G.; Dichio, B.; Sofo, A. Differential olive grove management regulates the levels of primary metabolites in xylem sap. Plant Soil 2021, 460, 281-296. [CrossRef]

77. Kim, H.K.; Choi, Y.H.; Verpoorte, R. NMR-based metabolomic analysis of plants. Nat. Protoc. 2010, 5, 536-549. [CrossRef]

78. Mahrous, E.A.; Farag, M.A. Two dimensional NMR spectroscopic approaches for exploring plant metabolome: A review. J. Adv. Res. 2015, 6, 3-15. [CrossRef]

79. Müller, H.; Berg, C.; Landa, B.B.; Auerbach, A.; Moissl-Eichinger, C.; Berg, G. Plant genotype-specific archaeal and bacterial endophytes but similar Bacillus antagonists colonize Mediterranean olive trees. Front. Microbiol. 2015, 6, 138. [CrossRef]

80. Mercado-Blanco, J.; RodrÍguez-Jurado, D.; Hervás, A.; Jiménez-DÍaz, R.M. Suppression of Verticillium wilt in olive planting stocks by root-associated fluorescent Pseudomonas spp. Biol. Control 2004, 30, 474-486. [CrossRef]

81. Weller, D.M. Pseudomonas Biocontrol Agents of Soilborne Pathogens: Looking Back Over 30 Years. Phytopathology 2007, 97, 250-256. [CrossRef] [PubMed]

82. Loper, J.E.; Hassan, K.A.; Mavrodi, D.; Ii, E.W.D.; Lim, C.K.; Shaffer, B.T.; Elbourne, L.D.H.; Stockwell, V.O.; Hartney, S.L.; Breakwell, K.; et al. Comparative Genomics of Plant-Associated Pseudomonas spp.: Insights into Diversity and Inheritance of Traits Involved in Multitrophic Interactions. PLoS Genet. 2012, 8, e1002784. [CrossRef] [PubMed]

83. Ofek, M.; Hadar, Y.; Minz, D. Ecology of Root Colonizing Massilia (Oxalobacteraceae). PLoS ONE 2012, 7, e40117. [CrossRef] [PubMed]

84. López-Escudero, F.; Del Río, C.; Caballero, J.; Blanco-López, M. Evaluation of Olive Cultivars for Resistance to Verticillium dahliae. Eur. J. Plant Pathol. 2004, 110, 79-85. [CrossRef]

85. Martos-Moreno, C.; López-Escudero, F.J.; Blanco-López, M.A. Resistance of Olive Cultivars to the Defoliating Pathotype of Verticillium dahliae. HortScience 2006, 41, 1313-1316. [CrossRef]

86. D’Attoma, G.; Morelli, M.; Saldarelli, P.; Saponari, M.; Giampetruzzi, A.; Boscia, D.; Savino, V.N.; De La Fuente, L.; Cobine, P.A. Ionomic Differences between Susceptible and Resistant Olive Cultivars Infected by Xylella fastidiosa in the Outbreak Area of Salento, Italy. Pathogens 2019, 8, 272. [CrossRef]

87. Vergine, M.; Meyer, J.B.; Cardinale, M.; Sabella, E.; Hartmann, M.; Cherubini, P.; De Bellis, L.; Luvisi, A. The Xylella fastidiosaResistant Olive Cultivar "Leccino" Has Stable Endophytic Microbiota during the Olive Quick Decline Syndrome (OQDS). Pathogens 2019, 9, 35. [CrossRef] [PubMed]

88. Trapero, C.; Díez, C.M.; Rallo, L.; Barranco, D.; López-Escudero, F.J. Effective inoculation methods to screen for resistance to Verticillium wilt in olive. Sci. Hortic. 2013, 162, 252-259. [CrossRef]

89. Luvisi, A.; Aprile, A.; Sabella, E.; Vergine, M.; Nicolì, F.; Nutricati, E.; Miceli, A.; Negro, C.; Bellis, L. De Xylella fastidiosa subsp. pauca (CoDiRO strain) infection in four olive (Olea europaea L.) cultivars: Profile of phenolic compounds in leaves and progression of leaf scorch symptoms. Phytopathol. Mediterr. 2017, 56, 259-273. [CrossRef]

90. Girelli, C.R.; Del Coco, L.; Scortichini, M.; Petriccione, M.; Zampella, L.; Mastrobuoni, F.; Cesari, G.; Bertaccini, A.; D'Amico, G.; Contaldo, N.; et al. Xylella fastidiosa and olive quick decline syndrome (CoDiRO) in Salento (southern Italy): A chemometric $1 \mathrm{H}$ NMR-based preliminary study on Ogliarola salentina and Cellina di Nardò cultivars. Chem. Biol. Technol. Agric. 2017, 4, 1-9. [CrossRef]

91. Girelli, C.R.; Angilè, F.; Del Coco, L.; Migoni, D.; Zampella, L.; Marcelletti, S.; Cristella, N.; Marangi, P.; Scortichini, M.; Fanizzi, F.P. 1H-NMR Metabolite Fingerprinting Analysis Reveals a Disease Biomarker and a Field Treatment Response in Xylella fastidiosa subsp. pauca-Infected Olive Trees. Plants 2019, 8, 115. [CrossRef] [PubMed]

92. Markakis, E.A.; Tjamos, S.E.; Antoniou, P.P.; Roussos, P.A.; Paplomatas, E.J.; Tjamos, E.C. Phenolic Responses of Resistant and Susceptible Olive Cultivars Induced by Defoliating and Nondefoliating Verticillium dahliae Pathotypes. Plant Dis. 2010, 94, 1156-1162. [CrossRef] [PubMed] 